Corresponding author: jameshic@usc.edu

(c) 2020 Welter et al. This article is distributed under the terms of the Creative Commons Attribution-NonCommercial License, which permits reuse and redistribution, except for commercial purposes, provided that the original author and source are credited.

Ontology term: neoplasm of the breast

Published by Cold Spring Harbor Laboratory Press

doi:10.1101/mcs.a005819

\section{Treatment response and tumor evolution: lessons from an extended series of multianalyte liquid biopsies in a metastatic breast cancer patient}

\author{
Lisa Welter, ${ }^{1}$ Liya Xu ${ }^{1}$ Dillon McKinley, ${ }^{1}$ Angel E. Dago, ${ }^{2}$ Rishvanth K. Prabakar, ${ }^{1}$ \\ Sara Restrepo-Vassalli, ${ }^{1}$ Kevin Xu, ${ }^{1}$ Mariam Rodriguez-Lee, ${ }^{1}$ Anand Kolatkar, ${ }^{1}$ \\ Rafael Nevarez, ${ }^{1}$ Carmen Ruiz, ${ }^{1}$ Jorge Nieva, ${ }^{3}$ Peter Kuhn, ${ }^{1,3,4}$ and James Hicks ${ }^{1}$ \\ ${ }^{1}$ Convergent Science Institute in Cancer, Michelson Center for Convergent Bioscience, University of Southern \\ California, Los Angeles, California 90089, USA; ${ }^{2}$ The Scripps Research Institute, La Jolla, California 92037, \\ USA; ${ }^{3}$ Keck School of Medicine, University of Southern California, Los Angeles, California 90033, USA; ${ }^{4}$ Viterbi \\ School of Engineering, University of Southern California, Los Angeles, California 90089, USA
}

Abstract Currently, clinical characterization of metastatic breast cancer is based on tissue samples taken at time of diagnosis. However, tissue biopsies are invasive and tumors are continuously evolving, which indicates the need for minimally invasive longitudinal assessment of the tumor. Blood-based liquid biopsies provide minimal invasive means for serial sampling over the course of treatment and the opportunity to adjust therapies based on molecular markers. Here, we aim to identify cellular changes that occur in breast cancer over the lifespan of an affected patient through single-cell proteomic and genomic analysis of longitudinally sampled solid and liquid biopsies. Three solid and 17 liquid biopsies from peripheral blood of an $\mathrm{ER}^{+} / \mathrm{HER} 2^{-}$metastatic breast cancer patient collected over 4 years and eight treatment regimens were analyzed for morphology, protein expression, copynumber alterations, and single-nucleotide variations. Analysis of 563 single morphometrically similar circulating tumor cells (CTCs) and 13 cell-free DNA (cfDNA) samples along with biopsies of the primary and metastatic tumor revealed progressive genomic evolution away from the primary tumor profiles, along with changes in ER expression and the appearance of resistance mutations. Both the abundance and the genomic alterations of CTCs and cfDNA were highly correlated and consistent with genomic alterations in the tissue samples. We demonstrate that genomic evolution and acquisition of drug resistance can be detected in real time and at single-cell resolution through liquid biopsy analytes and highlight the utility of liquid biopsies to guide treatment decisions.

[Supplemental material is available for this article.]

\section{INTRODUCTION}

Treatment strategies for breast tumors are based on histological and molecular characteristics of tissue samples taken at time of diagnosis and only repeated in the case of metastatic relapse. Current clinical practice faces the challenge of tracing tumor evolution across multiple lines of therapy as well as accounting for tumor heterogeneity and its effects on treatment response (Vignot et al. 2012; Parikh et al. 2019). In contrast, liquid biopsies offer the potential to assess the state of a cancer at multiple time points over the course of treatment with the opportunity to guide therapeutic decisions in real time regardless of tissue of origin. 
COLD SPRING HARBOR Molecular Case Studies
Monitoring genomic evolution at single-cell level
In this extensive case study, we explore the value and feasibility of longitudinal multianalyte liquid biopsies as a minimally invasive tool to monitor tumor evolution under therapeutic pressure and acquired drug resistance in a hormone-positive metastatic breast cancer patient.

Over the past two decades, circulating tumor cells (CTCs) and cell-free DNA (cfDNA) have been intensely studied as a means to gain access to tumor-derived content through minimally invasive procedures in order to assess drug response, monitor tumor evolution, and detect drug resistance (Navin et al. 2011; Murtaza et al. 2013; Bettegowda et al. 2014; Wang et al. 2020). cfDNA analysis has become a popular tool to test for acquired resistance mutations across various cancer types such as lung, prostate, colorectal, and breast cancer and is heavily studied for the diagnosis, prognosis, and monitoring of cancers (Dawson et al. 2013; Murtaza et al. 2015; Abbosh et al. 2017; Wyatt et al. 2017; O'Leary et al. 2018; Ahlborn et al. 2019). Although cfDNA can provide valuable insight for targeted drug selection, these tests lack information on protein expression as well as single-cell resolution to characterize genomic heterogeneity available from CTCs. The presence of CTCs and CTC clusters has been associated with reduced progression-free and overall survival, yet enumeration alone is insufficient in capturing both the heterogeneity of the disease as well as the mechanisms of drug resistance (Cristofanilli et al. 2004; Aceto et al. 2014; Carlsson et al. 2014). Hence, recent efforts have focused on the combined proteo-genomic characterization of CTCs to identify common alterations and to detect druggable targets, with the first clinically actionable breakthrough in castrate-resistant prostate cancer (Scher et al. 2018). Today, it is well established that cfDNA and CTCs are easily accessible surrogates for solid biopsies that are representative of the primary and metastatic tissues (Palmirotta et al. 2018), and although they have been largely studied in parallel, the trend has shifted to a more comprehensive liquid biopsy with the combined analysis of CTCs, cfDNA, and other blood-based analytes (Rossi et al. 2018; Gorges et al. 2019; Heitzer et al. 2019; Kasimir-Bauer et al. 2019; Morad et al. 2019). Yet there is a need to demonstrate the value of repeated multianalyte liquid biopsy assessment for monitoring patients over the entire time course of the disease.

This unique index case presented an opportunity to assess 17 sequential blood draws collected over 4 years and eight treatment regimens. Through genomic and proteomic characterization of single CTCs and CfDNA, we observed the sequential acquisition of cancer driver and drug resistance mutations in light of the patient's clinical status. Our findings not only shed light into the relationship between CTCs and cfDNA, but also highlight how both analytes can be leveraged for precision medicine.

\section{RESULTS}

\section{Clinical History and Sample Collection}

The patient was first diagnosed in April 2012 with metastatic breast cancer with metastases to the lung, lymph nodes, and bone. Histological assessment of her breast tissue biopsy found strong staining for estrogen receptor (ER) with $100 \%$ positive nuclei, which indicates a strong dependence of the tumor on the ER signaling pathway. Cells were weakly positive for progesterone receptor (PR) with 2\%-3\% nuclei staining. No ERBB2/neu gene amplification was detected in the neoplastic cell population. As a result, she was started on an aromatase inhibitor. In October 2013, she was enrolled in a clinical study (PSOC0086) (Rodriguez-Lee et al. 2018) and contributed 17 sequential blood draws at clinical examinations over a 4-year period. Analysis of each blood sample included the enumeration and characterization of CTCs, quantification of cfDNA and circulating tumor DNA (ctDNA) fraction, and genomic analysis of both CTCs and cfDNA with the high-definition single-cell assay (HDSCA) workflow (Fig. 1A). CTCs 


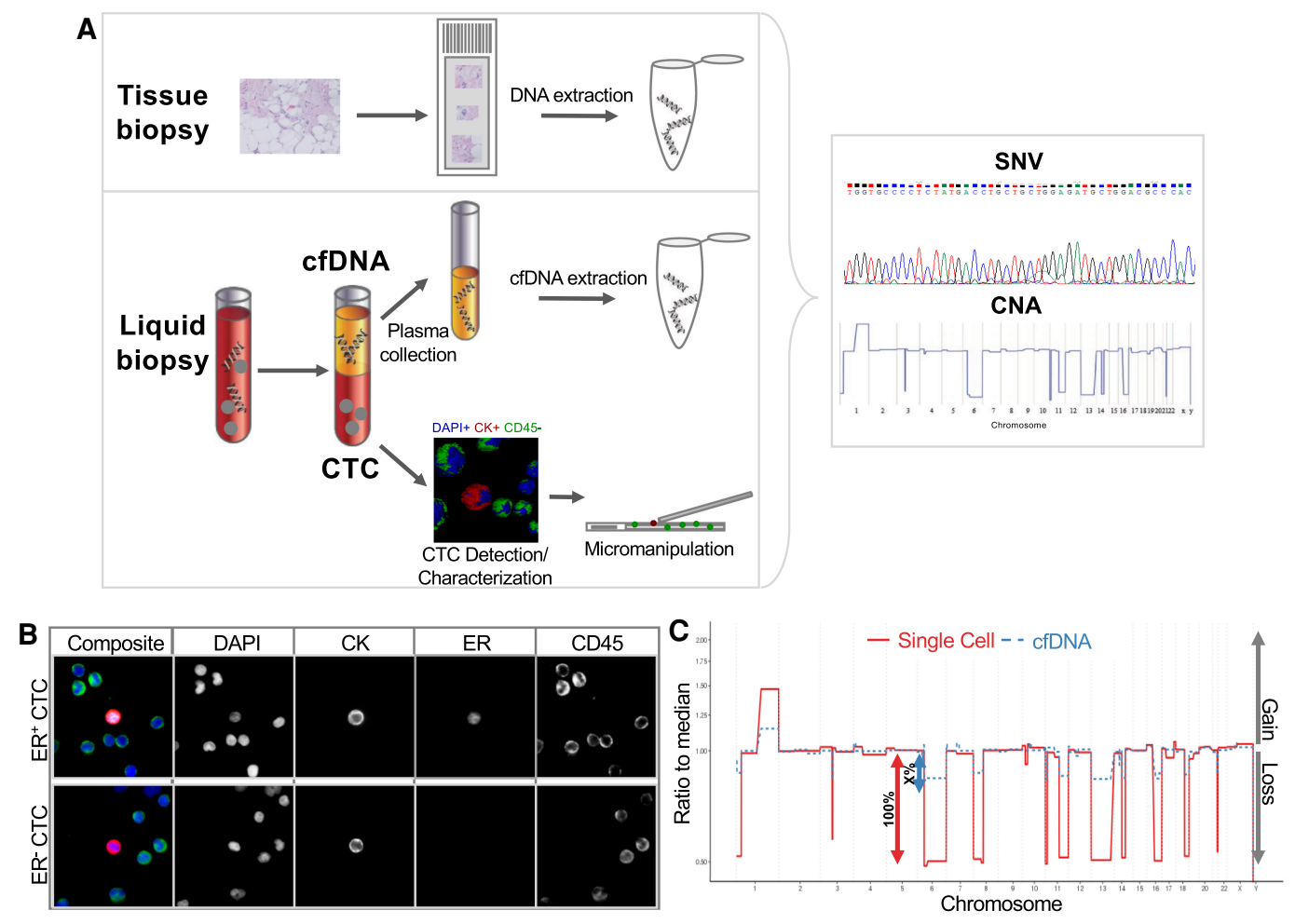

Figure 1. Schematic overview of the high-definition single-cell analysis (HDSCA) workflow for circulating tumor cell (CTC) characterization and cell-free DNA (cfDNA) analysis. (A) Blood samples were centrifuged and plasma was collected for cfDNA analysis. The remaining blood underwent erythrocyte lysis and nucleated cells were plated onto custom microscopy slides. To visualize CTCs among white blood cells, slides were stained with DAPI (DNA), CD45 (WBC marker), CK- (epithelial marker), and ER (CTC characterization). Candidate cells were isolated by micromanipulation and underwent whole-genome amplification. Polymerase chain reaction (PCR) products and extracted cfDNA were analyzed for copy-number alterations (CNAs) and single-nucleotide variations (SNVs). (B) Representative images of $E^{+}$and $E R^{-}$CTCs. Nuclei are stained with DAPI (blue) and antibodies against CKs (red), ER (white), and CD45 (green). (C) Circulating tumor DNA (ctDNA) content was approximated based on the amplitudes of CNAs. Single cells are per definition 100\% of tumor DNA, whereas cfDNA is a mix of nonmutated white blood cells (WBCs)/healthy tissue and tumor DNA. The height of the ctDNA amplitudes marks the tumor content. ctDNA content was estimated based on the ratio of CNA amplitudes between cfDNA and single-cell profiles.

were identified as DAPI and pan-Cytokeratin (CK)-positive, cluster of differentiation 45 (CD45)-negative events and further classified for ER expression. Representative images of $\mathrm{ER}^{+/-} \mathrm{CTC}$ are shown in Figure 1B. The ctDNA fractions were approximated based on comparison of the segmented copy-number alteration (CNA) amplitudes in cfDNA with those from pure single-cell DNA with a limit of sensitivity at $~ 5 \%$ tumor DNA (Fig. 1C).

At the time of the first blood draw in October 2013 the patient exhibited increasing metastatic burden and was switched from first-line treatment (letrozole) to fulvestrant. During the fulvestrant treatment (draws 1-3), her tumor markers (CA 27.29) and CTC counts increased. However, at draw 3 the fraction of $\mathrm{ER}^{+} \mathrm{CTC}$ decreased dramatically. Because of increasing pain and rising tumor marker she was switched in January 2014 to a combination of an mTOR inhibitor (everolimus) and an aromatase inactivator (exemestane) (draws 4 and 5). Tumor markers increased during this treatment, and the CTC counts increased drastically to $>3000 \mathrm{CTC} / \mathrm{mL}$. In August 2014, a needle biopsy of the liver confirmed a visceral crisis, extensively involved with metastatic adenocarcinoma, and her therapy was changed to a two- 
agent chemotherapy (capecitabine and paclitaxel) (draws 6-11). Drastic decreases in both CA 27.29 levels and CTC counts were observed in response to this therapy, and analytes remained low while she received chemotherapy. In October 2015, because of adverse events associated with cytotoxic therapy, her treatment was changed back to ER deprivation therapy (fulvestrant together with palbociclib) until December 2016 (draws 12-16). Tumor markers and CTCs remained relatively low through that period until December (draw 16) when both CA 27.29 and CTC counts again rose dramatically. Her treatment was changed back to chemotherapy (carboplatin), which led to an initial decrease in tumor markers. However, after a change in chemotherapeutic agents (from carboplatin to capecitabine), her CA 27.29 levels again rose dramatically as did the CTC count (draw 17). Final paclitaxel treatment following the capecitabine regimen was also ineffective and the patient succumbed to the disease shortly thereafter. The treatment history along with CTC counts and CA 27.29 levels at each examination are shown in Figure 2. Details from the clinical narrative are presented in Supplemental Data (Supplemental Fig. S1).

\section{ER Expression Is Related to Treatment Response}

Of the 17 collected blood draws, 12 draws had $>5 \mathrm{CTCs} / \mathrm{mL}$ blood and four draws had $>3000 \mathrm{CTCs} / \mathrm{mL}$. Examination of ER protein expression of CTCs by immunofluorescence found that ER positivity fluctuated drastically across draws. Interestingly, ER positivity decreased drastically in response to first-line fulvestrant treatment (draws 1-3), but did not decrease equally during second line of fulvestrant treatment in 2016 (draws 14-16). Overall, ER ${ }^{+}$CTCs represented the majority of cells across draws.

\section{CTC Enumeration Is Correlated with ctDNA Fraction, CA 27.29 Levels, and Disease State}

Next, we assessed whether the levels of liquid biopsy analytes were correlated. We found positive correlations between CTCs/mL, cfDNA concentrations, and ctDNA fractions (Fig. 3). Although we could not calculate the correlation between CA 27.29 and liquid biopsy analytes as CA 27.29 levels were not measured at the same draw date as liquid biopsy draws, it is evident that that their levels trend similarly. Increases in CA $27.29, \mathrm{CTCs} / \mathrm{mL}$, ctDNA fractions, and cfDNA concentration were all associated with disease progression.

\section{CNA Analysis of CTCs and Tissue Biopsies Traces Tumor Lineage}

To examine the extent of genomic heterogeneity at time of enrollment, we tested single cells detected by the HDSCA for CNAs. Candidate cells were isolated by micromanipulation for lowpass whole-genome sequencing and CNA profiling. Genomic analysis of 73 single CTCs of the first time point revealed three closely related subclones apparently derived from a common ancestor and exhibiting a sequential increase in CNA complexity (Fig. 4A). Truncal events in all subclones include segmental losses on Chromosomes 1p, 6q (ESR1), 11p/q (ATM), 13q (BRCA2, FOXO1A, RB1), 14q,16q (CDH1, CDH11) plus a gain of 1q (ABL2, ELK4, MDM4) and focal deletions on 3p (FOXP1), and 21q (Supplemental Fig. S2). Additional CNAs in subclones 2 and 3 include losses on 8p and 18q and amplifications on 11q (CCND1), from which we infer progressive evolution. To confirm the tumorous origin of these cells, bulk tissue biopsies of the primary breast as well as bone and liver metastases were assessed for CNAs (Fig. 4B). Comparative analysis of single cells from draw 1 with bulk tissue biopsies from primary breast and metastatic sites revealed that tumors in primary breast and bone were dominated by subclone 1 cells, whereas the later liver metastasis was comprised of nearly $100 \%$ subclone 2 cells.

Expanding our single-cell analysis to the remaining blood draws, we found that virtually all analyzed CTCs clustered with one of the three subclones, regardless of the blood draw, up until draw 16. Few exceptions were rare intermediate subclones, which shed light on how the three subclones formed (Supplemental Fig. S3). Three and a half years after enrollment (draw 


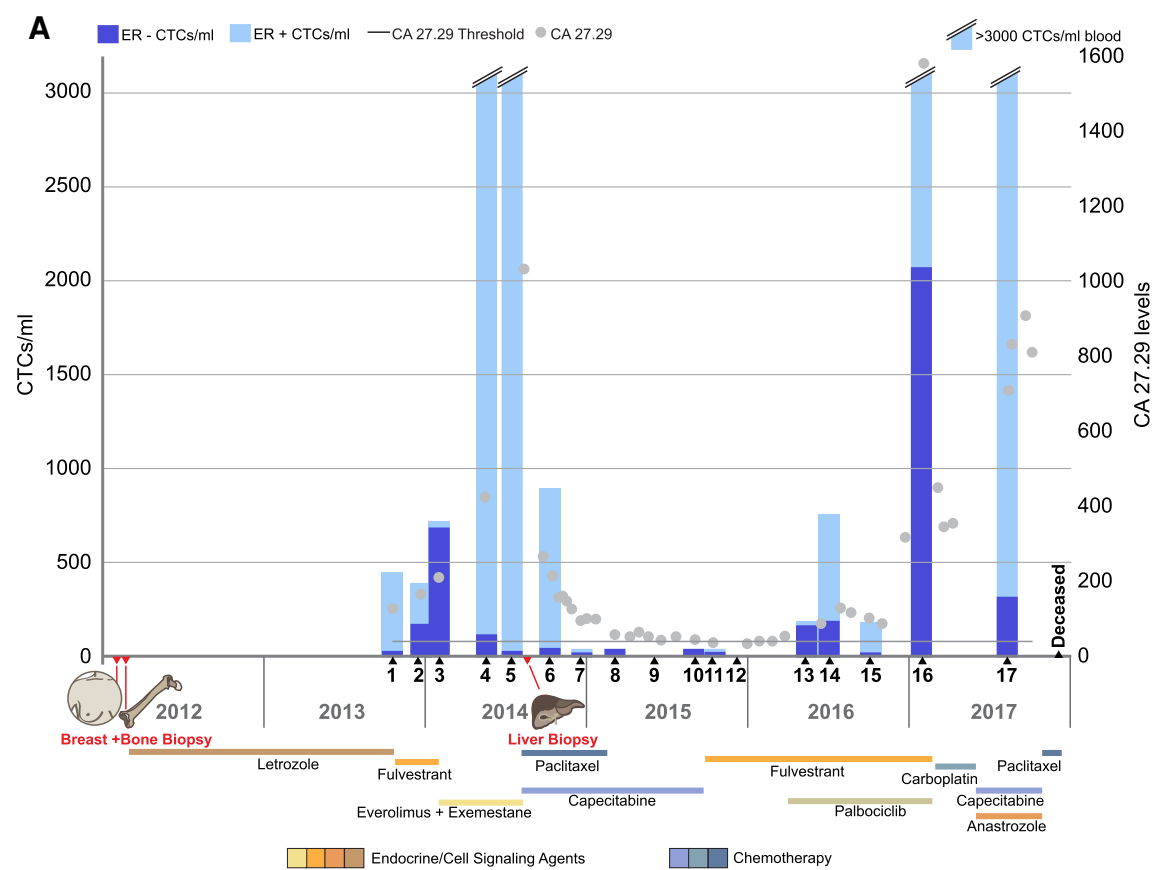

B

\begin{tabular}{|c|c|c|c|c|c|c|c|}
\hline Draw & Draw Date & Treatment Period & Therapy at time of Draw & CTCs/mI & $\%$ ER+ CTCS & $\begin{array}{l}\text { [cfDNA] (ng/ml } \\
\text { plasma) }\end{array}$ & $\begin{array}{l}\text { ctDNA } \\
\text { fraction }(\%)\end{array}$ \\
\hline 1 & 10/14/13 & 10/14/2013 - 01/23/2014 & Fulvestrant & 386.2 & 92.6 & N/A & N/A \\
\hline 2 & $12 / 19 / 13$ & 10/14/2013 - 01/23/2014 & Fulvestrant & 333.7 & 43.8 & N/A & N/A \\
\hline 3 & 1/27/14 & $01 / 27 / 2014$ - 08/25/2014 & Fulvestrant $\rightarrow$ Exemestane/Everolimus & 668.3 & 1.2 & $N / A$ & N/A \\
\hline 4 & $5 / 16 / 14$ & 01/27/2014 - 08/25/2014 & Exemestane/Everolimus & 14587 & 96.4 & N/A & 22.2 \\
\hline 5 & $7 / 11 / 14$ & $01 / 27 / 2014-08 / 25 / 2014$ & Exemestane/Everolimus & 61053 & 98.7 & 288.2 & 31.7 \\
\hline 6 & $10 / 6 / 14$ & 08/27/2014 - 12/30/2014 & Capecitabine/Paclitaxel & 839.1 & 92.6 & 40.7 & 9.5 \\
\hline 7 & $12 / 22 / 14$ & 08/27/2014 - 12/30/2014 & Capecitabine/Paclitaxel & 2.7 & 75.0 & 29.48 & 14.1 \\
\hline 8 & $3 / 2 / 15$ & 1/19/2015 - 10/26/2015 & Capecitabine & 6.9 & N/D & 53.35 & $<5$ \\
\hline 9 & $6 / 15 / 15$ & 1/19/2015 - 10/26/2015 & Capecitabine & 0 & N/D & 8.085 & $<5$ \\
\hline 10 & $8 / 31 / 15$ & 1/19/2015 - 10/26/2015 & Capecitabine & 3.5 & N/D & 11.275 & $<5$ \\
\hline 11 & $10 / 12 / 15$ & 1/19/2015 - 10/26/2015 & Capecitabine & 0.8 & N/D & 54.45 & $<5$ \\
\hline 12 & $12 / 28 / 15$ & 10/28/2015 - 12/23/2016 & Fulvestrant & 0 & N/D & 31.35 & $<5$ \\
\hline 13 & $5 / 9 / 16$ & 10/28/2015 - 12/23/2016 & $\begin{array}{l}\text { Fulvestrant/Palbociclib (Palbociclib } \\
\text { added 03/21/2016) }\end{array}$ & 139.8 & N/D & 11.22 & 16.9 \\
\hline 14 & $1 / 7 / 16$ & 10/28/2015 - 12/23/2016 & Fulvestrant/Palbociclib & 712 & 76.9 & 24.42 & 12.4 \\
\hline 15 & $9 / 30 / 16$ & 10/28/2015 - 12/23/2016 & Fulvestrant/Palbociclib & 133 & 79.6 & 10.6 & 10 \\
\hline 16 & $1 / 23 / 17$ & $01 / 16 / 2017-04 / 14 / 2017$ & Carboplatin & 66000 & 29.1 & 503.25 & 48.8 \\
\hline \multirow[t]{2}{*}{17} & $8 / 4 / 17$ & $5 / 10 / 2017-11 / 16 / 2017$ & $\begin{array}{c}\text { Capecitabine (Anastrozole added } \\
8 / 17 / 2017)\end{array}$ & 8932 & 89.2 & 44 & 14.3 \\
\hline & & 11/17/2017 - & Paclitaxel & & & & \\
\hline
\end{tabular}

Figure 2. Treatment history and liquid biomarker evaluation (A) CTC counts (blue bars) and serum marker CA 27.29 (gray dots) evaluation over time. The normalized proportion of ER ${ }^{+}$(light blue) and ER (dark blue) are denoted in the bars. (B) Summary of draw dates, therapy at time of blood draw, CTC abundance, and ER expression as well as cfDNA/ctDNA abundance. (N/A) Not available, (N/D) not detectable.

16) we discovered a new genomically related subclone 4, which had acquired additional chromosomal gains of Chromosome 5, 6p, 8q, 16p, and 20, containing genes such as MAP3K1, APC, MYC, ASXL1, and ZNF217 (Fig. 4C,D; Supplemental Figs. S2, S4). Interestingly, CTCs across the four genomic subtypes were phenotypically similar when compared for nuclear and cellular area, eccentricity, and perimeter (Supplemental Fig. S5).

Analysis of 42 commonly altered genes implicated in breast cancer finds that CNAs present at time of enrollment span a wide variety of genes implicated in apoptosis, DNA repair, 

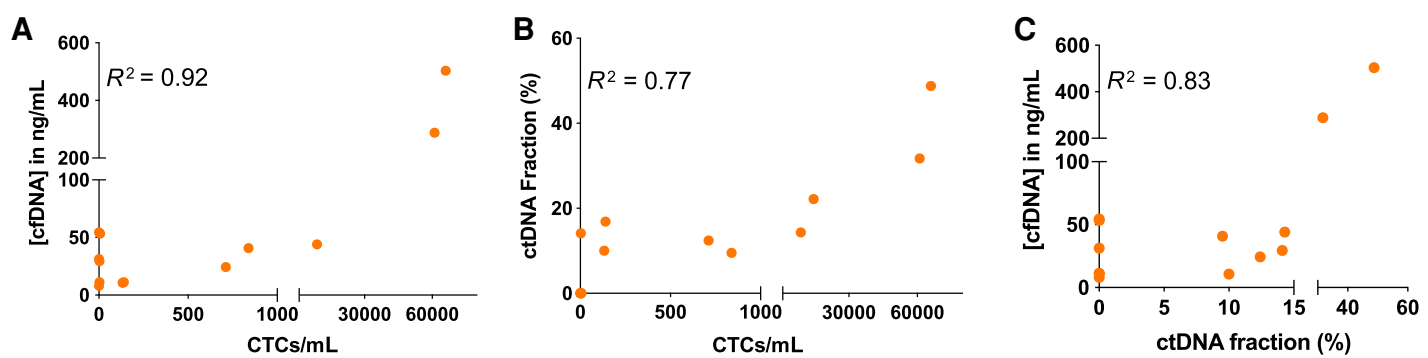

Figure 3. Correlation between $\mathrm{CTCs} / \mathrm{mL}$, ctDNA fraction, and cfDNA concentration. (A) Correlation between $\mathrm{CTCs} / \mathrm{mL}$ and the concentration of cfDNA. Pearson correlation coefficient $R^{2}=0.92$ and two-tailed $P$-value $<0.0001$. (B) Correlation between $\mathrm{CTCs} / \mathrm{mL}$ and the ctDNA fraction. Pearson correlation coefficient $R^{2}=$ 0.77 and two-tailed $P$-value $<0.0001$. (C) Correlation between the ctDNA fraction and cfDNA concentration. Pearson correlation coefficient $R^{2}=0.83$ and two-tailed $P$-value $<0.0001$. ctDNA fractions $<5 \%$ were considered 0 .

cytokinesis, and $\mathrm{G}_{1} / \mathrm{S}$-phase transition (Table 1). In contrast, CNAs gained with subclone 4 primarily affect cell cycle control. Additionally, subclones 1-3 were dominated by copy-number losses, whereas subclone 4 acquired mainly copy-number gains. Although the abundance of the clones varied among draws, we found that subclone 2 was the most prominent clone in nine of the 11 draws with high CTC counts (Fig. 4C,D).

\section{CNA Analysis of cfDNA Reveals a Genomic Relationship with CTCs}

Next, we assessed how the abundance and genomic content of cfDNA are related to CTCs and solid tissue biopsies. cfDNA was extracted from draws 4-17 (plasma was not available from draws 1-3) and sequenced for CNA profiling. We found not only that ctDNA fraction, cfDNA concentration, and CTC abundance were positively correlated (Fig. 3), but also that the CNA profiles of ctDNA represented the aggregate of CTC subclones (Fig. 4D). In particular, ctDNA CNA profiles reflect the most abundant CTC subclone per time point. Figure 4D contains an overlay of draw 5 cfDNA CNAs with subclone 2 and draw 16 cfDNA CNAs with subclone 4 showing the correspondence of genomic alterations and the differences in amplitude.

\section{ESR1 Mutation Analysis in Tissue Samples, cfDNA, and CTCs Uncovers Parallel Endocrine Resistance Evolution}

To explore the cause of hormone treatment failure, we used the Thermo Fisher Oncomine breast cancer panel to test cfDNA for SNVs. Oncomine test results revealed an ESR1 Y537N mutation at draw 5, which was collected after multiple rounds of hormone therapy, followed by a second ESR1 mutation (D538G) in draw 6 (Fig. 5A). Given the heterozygous deletion in Chromosome 6q in the region containing the ESR1 gene, a single mutation in the ESR1 gene resulted in complete loss of wild-type (WT) ER in affected cells. In the ninth blood draw a TP53 mutation was detected for the first time, but remained at low abundance. Draw 16 is the first time we find not only a new subclone based on CNA profiling, but also a mutation in PIK3CA (E542K) as well as an additional ESR1 mutation (Y537S). Overall, we detected a low SNV burden across all blood draws, with a majority of known endocrine resistance inducing ESR1 mutations.

To test whether the patient's tumor harbored any of these SNVs at the time of diagnosis, we performed whole-exome sequencing of the primary breast tissue and metastatic bone and liver biopsies and confirmed results by Sanger sequencing (Fig. 5B; Supplemental Fig. S6A). None of the mutations detected later in the plasma were found in the breast and bone 
A

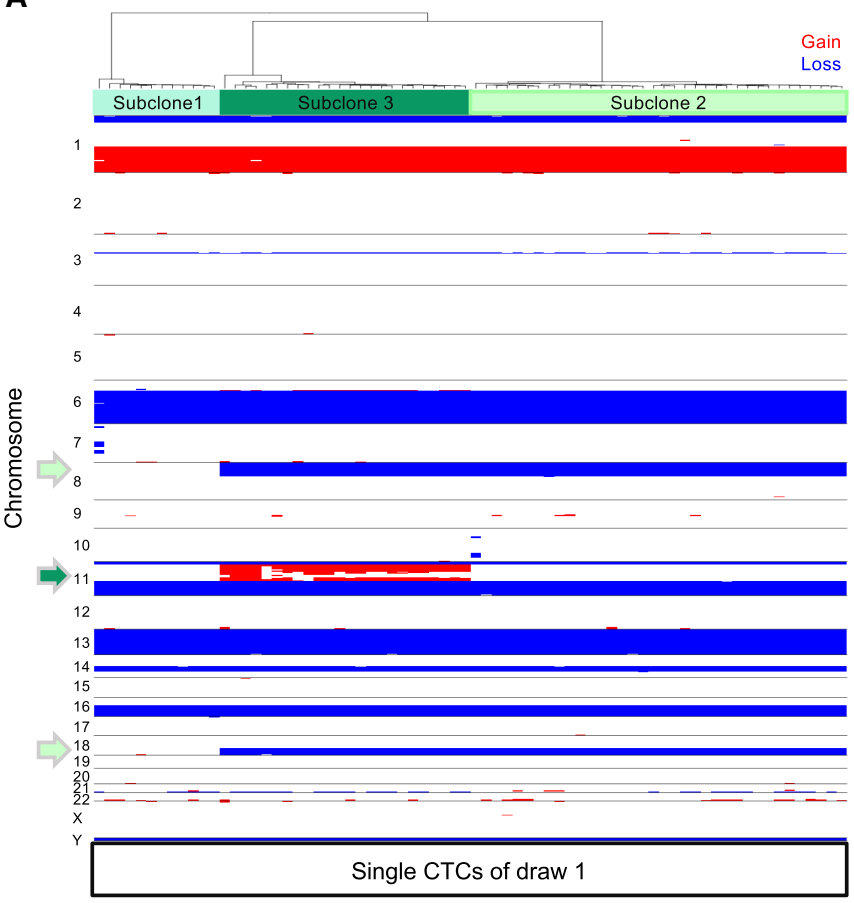

B

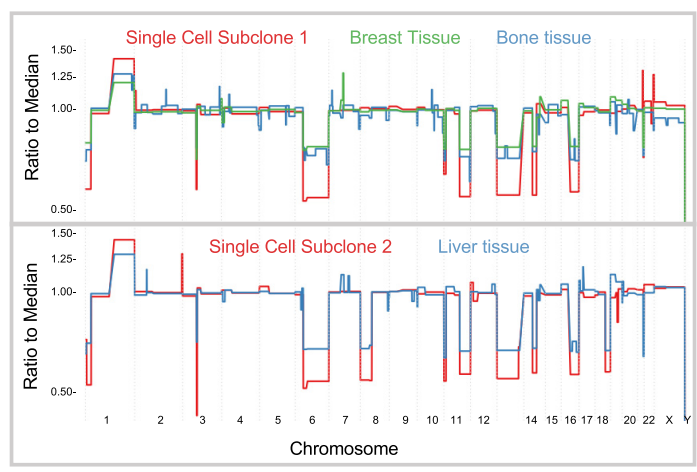

C

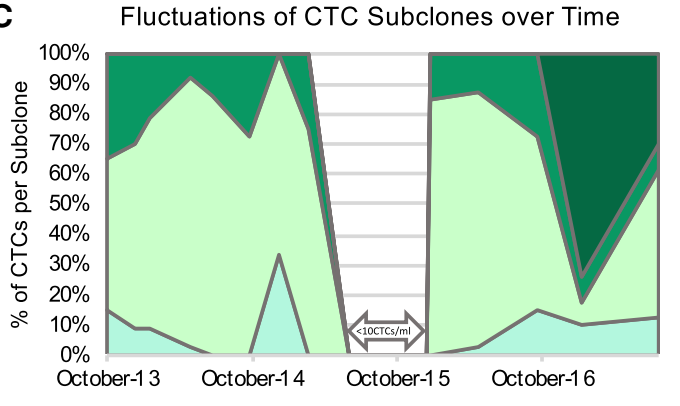

口Subclone 1 aSubclone 2 Subclone 3 -Subclone 4

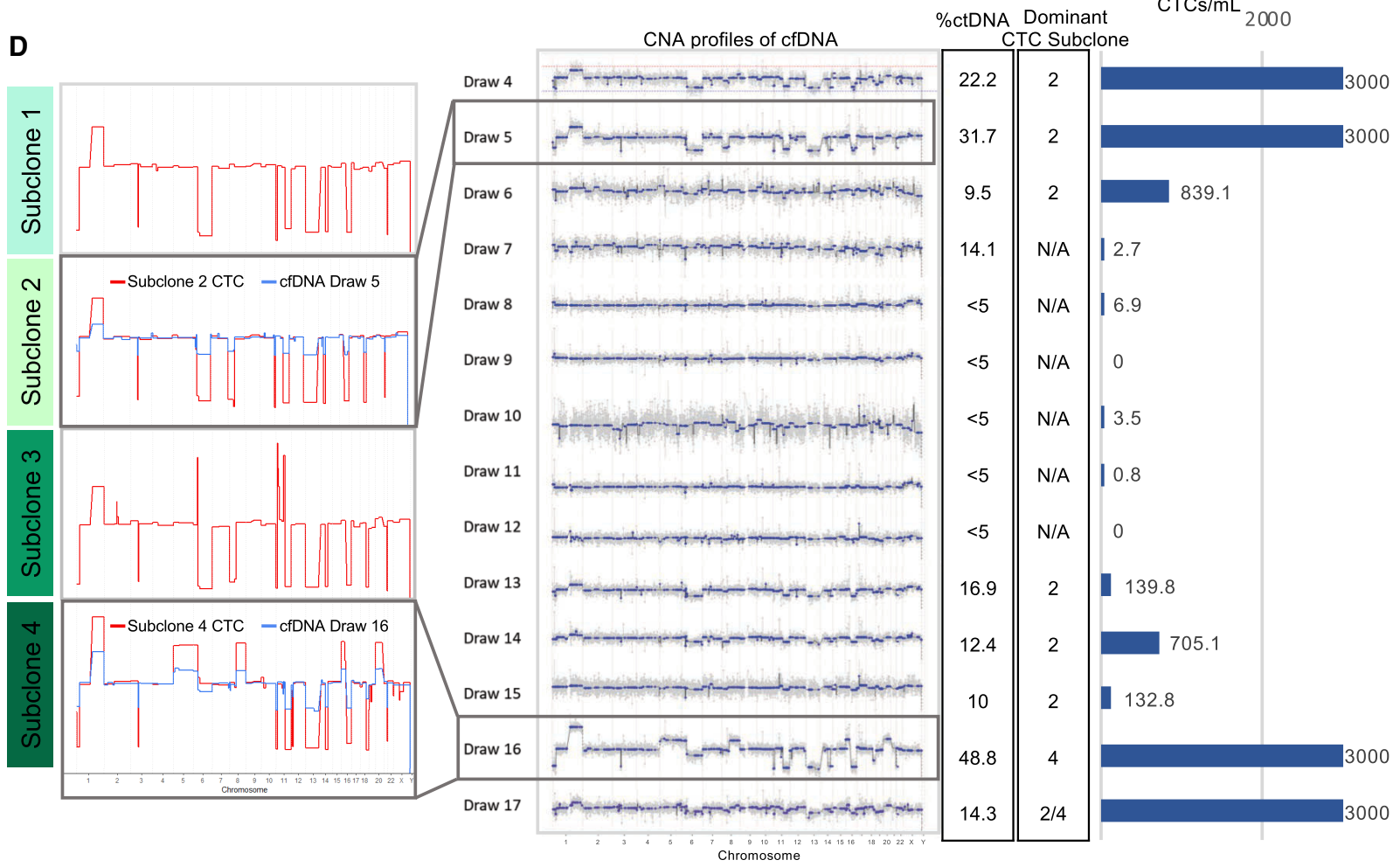

Figure 4. Copy-number alteration analysis of CTCs, tissue biopsies and cfDNA. (A) Heatmap of 73 CTCs isolated from draw 1. CTCs cluster into three distinct subclones. Copy-number gains are shown in red and losses in blue. (B) Direct comparison of tissue biopsies with specific CTC subclones. (C) Fluctuations of CTC subclone abundance across the 17 draws. Time points with less than 10 evaluable CTCs were excluded from analysis (draw 7-12). (D) Comparative analysis of ctDNA and CTC abundance and their genomic relationship. (Left) Representative CTCs of each subclone highlight genomic relationship across subclones. CTC CNA profiles of subclone 2 and 4 are superimposed with cfDNA CNA profile of draw 5 and 16, respectively. (Middle) cfDNA CNA profiles from draw 4-17. Plasma of earlier draws was not available for analysis. (Right) Percentage of ctDNA, most dominant subclone, and CTCs $/ \mathrm{mL}$ blood. 


\begin{tabular}{|c|c|c|c|c|c|}
\hline Gene & Subclone 1 & Subclone 2 & Subclone 3 & Subclone 4 & WBC \\
\hline ARID1A & Loss & Loss & Loss & Loss & None \\
\hline SF3B1 & None & None & None & None & None \\
\hline CASP8 & None & None & None & None & None \\
\hline SETD2 & None & None & None & None & None \\
\hline BAP1 & None & None & None & None & None \\
\hline PIK3CA & None & None & None & None & None \\
\hline MAP3К13 & None & None & None & None & None \\
\hline MAP3K1 & None & None & None & Gain & None \\
\hline$A P C$ & None & None & None & Gain & None \\
\hline ESR1 & Loss & Loss & Loss & None & None \\
\hline$A R I D 1 B$ & Loss & Loss & Loss & None & None \\
\hline MLL3 & None & None & None & None & None \\
\hline ZNF703 & None & Loss & Loss & None & None \\
\hline FGFR1 & None & Loss & Loss & None & None \\
\hline MYC & None & None & None & Gain & None \\
\hline CDKN2A & None & None & None & None & None \\
\hline GATA3 & None & None & None & None & None \\
\hline PTEN & None & None & None & None & None \\
\hline CCND1 & None & None & Gain & None & None \\
\hline CDKN1B & None & None & None & None & None \\
\hline KRAS & None & None & None & None & None \\
\hline ARID2 & None & None & None & None & None \\
\hline MLL2 & None & None & None & None & None \\
\hline SMARCD1 & None & None & None & None & None \\
\hline MDM2 & None & None & None & None & None \\
\hline TBX3 & None & None & None & None & None \\
\hline BRCA2 & Loss & Loss & Loss & Loss & None \\
\hline$R B 1$ & Loss & Loss & Loss & Loss & None \\
\hline$A K T 1$ & None & None & None & None & None \\
\hline $\mathrm{CDH} 1$ & Loss & Loss & Loss & Loss & None \\
\hline TP53 & None & None & None & None & None \\
\hline MAP2K4 & None & None & None & None & None \\
\hline NCOR1 & None & None & None & None & None \\
\hline NF1 & None & None & None & None & None \\
\hline ERBB2 & None & None & None & None & None \\
\hline BRCA1 & None & None & None & None & None \\
\hline SMAD4 & None & None & None & None & None \\
\hline STK11 & None & None & None & None & None \\
\hline AKT2 & None & None & None & None & None \\
\hline ASXL1 & None & None & None & Gain & None \\
\hline ZNF217 & None & None & None & Gain & None \\
\hline$A R$ & None & None & None & None & None \\
\hline
\end{tabular}

Copy-number alteration analysis of representative CTCs of the four subclones and a white blood cell (WBC) count for 42 commonly altered genes in breast cancer. Gains and losses are shown for four representative CTCs of each subclone and 1 representative WBC of draw 16. 
A

\begin{tabular}{|c|c|c|c|c|c|c|c|c|c|c|c|c|}
\hline $\begin{array}{l}\text { Blood } \\
\text { Draw }\end{array}$ & Gene & $\begin{array}{l}\text { AA } \\
\text { Change }\end{array}$ & $\operatorname{VAF}(\%)$ & $\begin{array}{c}\text { cfDNA fraction } \\
(\%)\end{array}$ & $\begin{array}{l}\text { VAF per } \\
\text { ctDNA fraction } \\
(\%)\end{array}$ & $\begin{array}{l}\text { Found in } \\
\text { CTCs }\end{array}$ & $\begin{array}{l}\text { Number of } \\
\text { MutWT } \\
\text { Cells }\end{array}$ & Position & $\begin{array}{c}\text { Mol Depth } \\
\text { (from UMI) }\end{array}$ & $\begin{array}{l}\text { Variants } \\
\text { (UMI) }\end{array}$ & $\begin{array}{l}\text { LOD (from } \\
\text { read count) }\end{array}$ & $\begin{array}{l}\text { Total Read } \\
\text { Count/ Locus }\end{array}$ \\
\hline 1 & ESR1 & Any & N/A & N/A & N/A & no & $0 / 17$ & & & & & \\
\hline 3 & ESR1 & Any & N/A & N/A & $\mathrm{N} / \mathrm{A}$ & no & $0 / 25$ & & & & & \\
\hline 5 & ESR1 & Y537N & 11.72 & 31.8 & 36.9 & yes & $1 / 23$ & chr6:152419921 & 239 & 28 & 0.65 & 780 \\
\hline \multirow{2}{*}{6} & ESR1 & Y537N & 3.41 & \multirow{2}{*}{9.5} & 68.2 & yes & $14 / 38$ & chr6:152419922 & 7587 & 259 & 0.05 & 36583 \\
\hline & ESR1 & D538G & 0.26 & & 5.2 & no & $0 / 38$ & chr6:152419926 & 7587 & 20 & 0.05 & 36589 \\
\hline 7 & ESR1 & Y537N & 0.24 & 14.1 & 1.7 & N/A & No CTCs & chr6:152419922 & 3718 & 8 & 0.05 & 20577 \\
\hline 8 & ESR1 & Y537N & 0.13 & $<5$ & 2.6 & $\mathrm{~N} / \mathrm{A}$ & No CTCs & chr6:152419922 & 3733 & 5 & 0.05 & 25944 \\
\hline 9 & TP53 & $\mathrm{R} 248 \mathrm{Q}$ & 0.10 & $<5$ & 2.0 & N/A & No CTCs & chr17:7577538 & 1936 & 2 & 0.1 & 13158 \\
\hline 10 & ESR1 & Y537N & 0.11 & $<5$ & 2.2 & N/A & No CTCs & chr6:152419922 & 1870 & 2 & 0.1 & 11142 \\
\hline 11 & $\begin{array}{l}\text { No Mut } \\
\text { found }\end{array}$ & & & $<5$ & 0.0 & N/A & No CTCs & & & & & \\
\hline \multirow{2}{*}{12} & ESR1 & Y537N & 0.10 & \multirow{2}{*}{$<5$} & 2.0 & \multirow{2}{*}{ N/A } & \multirow{2}{*}{ No CTCs } & chr6:152419922 & 2004 & 2 & 0.1 & 15644 \\
\hline & TP53 & R248Q & 0.20 & & 4.0 & & & chr17:7577538 & 1471 & 3 & 0.15 & 14634 \\
\hline \multirow{2}{*}{13} & ESR1 & Y537N & 1.15 & \multirow{2}{*}{16.9} & 6.8 & yes & $3 / 2$ & chr6:152419922 & 693 & 8 & 0.25 & 2892 \\
\hline & TP53 & $\mathrm{R} 248 \mathrm{Q}$ & 0.29 & & 1.7 & $\mathrm{ND}$ & $\mathrm{ND}$ & chr17:7577538 & 698 & 2 & 0.25 & 3171 \\
\hline 14 & ESR1 & Y537N & 3.69 & 12.4 & 29.7 & yes & $2 / 27$ & chr6:152419921 & 2466 & 91 & 0.1 & 13912 \\
\hline \multirow{2}{*}{15} & ESR1 & Y537N & 0.66 & \multirow{2}{*}{10.0} & 13.2 & yes & $5 / 15$ & chr6:152419922 & 3788 & 25 & 0.05 & 20197 \\
\hline & ESR1 & D538G & 0.10 & & 2.0 & yes & $5 / 15$ & chr6:152419926 & 3789 & 4 & 0.05 & 20197 \\
\hline \multirow{5}{*}{16} & $P \mid K 3 C A$ & E542K & 0.31 & \multirow{5}{*}{48.8} & 0.6 & yes & $1 / 15$ & chr3:178936082 & 3265 & 10 & 0.05 & 12680 \\
\hline & ESR1 & Y537N & 0.30 & & 0.6 & yes & $1 / 38$ & chr6:152419921 & 2994 & 9 & 0.1 & 10594 \\
\hline & ESR1 & Y537S & 0.07 & & 0.1 & no & $0 / 38$ & chr6:152419923 & 2994 & 2 & 0.1 & 10594 \\
\hline & ESR1 & D538G & 7.32 & & 15.0 & yes & $2 / 38$ & chr6:152419926 & 2992 & 219 & 0.1 & 10594 \\
\hline & TP53 & R248Q & 0.05 & & 0.1 & $\mathrm{ND}$ & ND & chr17:7577538 & 3680 & 2 & 0.05 & 13885 \\
\hline \multirow{5}{*}{17} & $P I K 3 C A$ & E542K & 0.11 & \multirow{5}{*}{14.3} & 0.7 & no & $0 / 5$ & 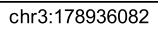 & 7482 & 8 & 0.05 & 54295 \\
\hline & ESR1 & Y537N & 2.75 & & 19.3 & yes & $12 / 34$ & chr6:152419922 & 5163 & 142 & 0.05 & 25057 \\
\hline & ESR1 & Y537S & 0.14 & & 0.9 & yes & $1 / 34$ & chr6:152419923 & 5163 & 7 & 0.05 & 25057 \\
\hline & ESR1 & D538G & 2.19 & & 15.3 & yes & $1 / 34$ & chr6:152419926 & 5162 & 113 & 0.05 & 25057 \\
\hline & TP53 & R248Q & 0.13 & & 0.9 & $\mathrm{ND}$ & ND & chr17:7577538 & 5544 & 7 & 0.05 & 37737 \\
\hline
\end{tabular}

B

C......ESR1WT

\begin{tabular}{|c|c|c|c|}
\cline { 2 - 4 } \multicolumn{1}{c|}{} & $\begin{array}{c}\text { Primary } \\
\text { Breast }\end{array}$ & $\begin{array}{c}\text { Bone } \\
\text { Metastasis }\end{array}$ & $\begin{array}{c}\text { Liver } \\
\text { Metastasis }\end{array}$ \\
\hline ESR1: Y537N & No & No & Yes \\
\hline ESR1: Y537S & No & No & No \\
\hline ESR1: D538G & No & No & No \\
\hline TP53: R248Q & N/D & No & Yes \\
\hline PIK3CA: E542K & No & No & No \\
\hline
\end{tabular}
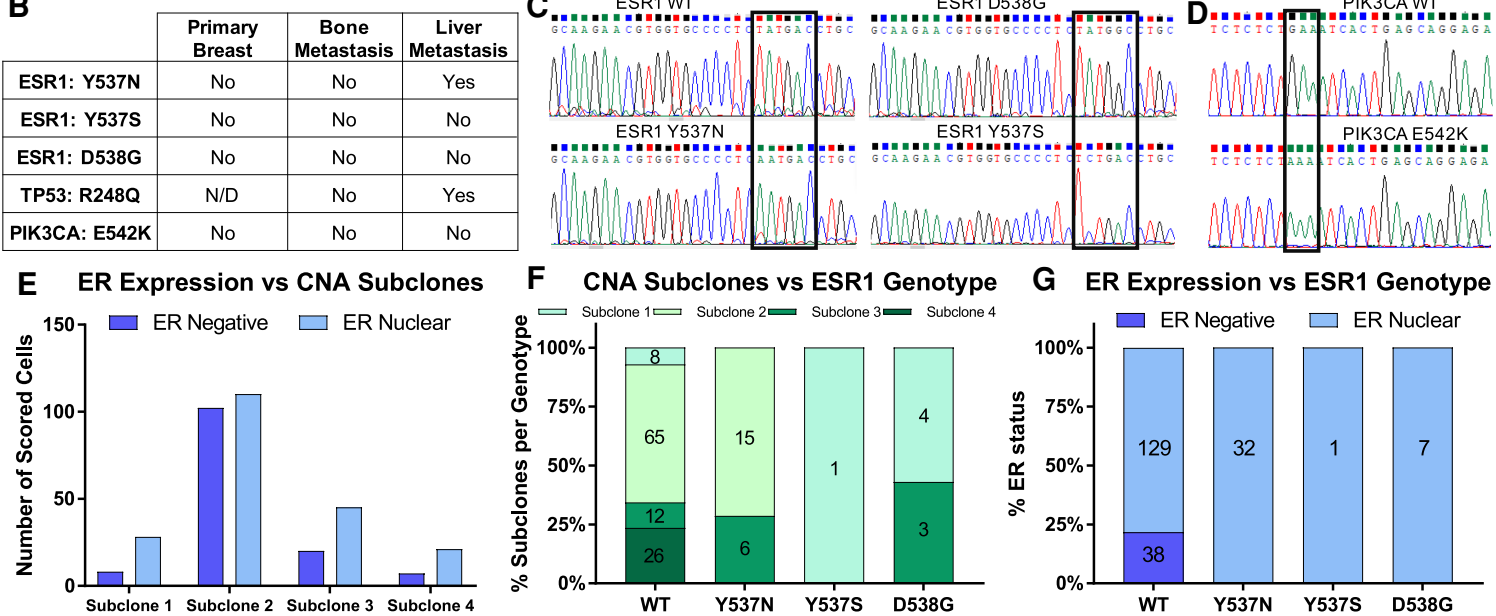

G ER Expression vs ESR1 Genotype

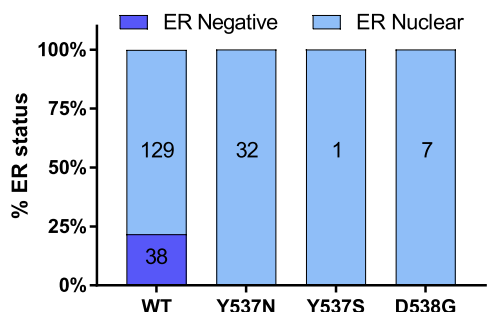

Figure 5. SNV analysis of cfDNA, tissue biopsies, and CTCs. (A) Overview of cfDNA mutation status by Oncomine Breast Cancer panel and comparison with single-cell Sanger sequencing. (B) Summary of wholeexome sequencing results of tissue biopsies for mutations detected in the ctDNA. (C) Representative examples of ESR1 Sanger sequencing traces of WT and mutant CTCs. (D) Representative examples of PIK3CA Sanger sequencing traces of WT and mutant CTCs. (E) ER expression per subclone across all CTC-positive draws. (F) Comparative analysis of CNA subclones and ESR1 genotype of single CTCs across all evaluated time points. Numbers indicate number of cells scored. (G) Comparative analysis of ER protein expression measured by immunofluorescence and ESR1 genotype of single CTCs across all evaluated time points. Numbers indicate number of cells scored. (N/A) Not available, (ND) not determined. 
biopsies, which were collected at the time of diagnosis. However, we detected the same Y537N mutation in the liver biopsy, which was taken 1.5 months after draw 5 . This indicates that the tumor likely initially developed by large chromosomal alterations that remained remarkably stable over many years, yet eventually evolved primarily through specific SNVs.

To pinpoint when the first ESR1 mutation emerged and to deconvolute the mutational heterogeneity of single cells, we designed an assay for single-cell SNV analysis to examine CTCs for ESR1 mutations. Leukocytes isolated from the same blood draw were used as controls (Supplemental Fig. S6A,B). None of the CTCs and WBCs isolated from draws 1 and 3 harbored the expected mutation (Fig. 5A). In contrast, CTCs, but not WBCs from draw 5 onward, exhibited the same Y537N mutation found at high variant allele fraction in the cfDNA and the liver metastasis. Also, in line with the cfDNA results, we detected Y537S and D538G mutations in CTCs of the later blood draws (draw 15-17). Representative ESR1 Sanger sequencing traces are shown in Figure 5C. Interestingly, mutations in amino acid 537 were mutually exclusive from those in amino acid 538 , indicating parallel mechanisms of resistance.

Out of the 19 instances of ESR1 mutations found in cfDNA with the Oncomine assay across the draws, only two were not detected at the single-cell level (Fig. 5A). However, these two mutations occurred at either very low frequency and/or low ctDNA fraction and could have been missed because of the limited number of cells sequenced. In contrast, all mutations detected at the single-cell level were found in the cfDNA by the Oncomine assay.

\section{ESR1 Mutations Occur Independently of CNAs, but Are Positively Associated with ER Protein Expression}

Next, we determined whether there was any association between ESR1 mutations, ER expression, and CNA-defined subclones. Despite their genomic differences, cells from the four subclones identified by CNA analysis were not associated with a specific ER expression phenotype (Fig. 5E), indicating that fluctuations in ER expression are independent of their gross chromosomal alterations. In addition, ESR1 mutations occurred independently of the subclones, signifying that ESR1 resistance has developed independently from the CNAs (Fig. 5F). Interestingly, all ESR1-mutated cells expressed nuclear ER protein as visualized by immunofluorescence (Fig. 5G). Thus, although cfDNA analysis by Oncomine provided higher apparent sensitivity, single-cell analysis was required to evaluate the distribution of the 537 and 538 mutations and associate mutations with ER protein expression.

\section{Co-occurrence of PIK3CA Mutation and Subclone 4 Marks the Point of Multitreatment Failure}

Finally, we tested whether there was an association between the occurrence of subclone 4 cells and the detection of PIK3CA mutations at draw 16, specifically whether PIK3CA mutations were exclusive to cells of subclone 4 . Single-cell SNV analysis of draw 16 found one CTC with the E542K mutation out of 16 sequenced CTCs (Fig. 5D). Interestingly, the CNA profile of the E542K-mutated cell exhibits the same gains and losses typical of subclone 4, which indicates that the PIK3CA point mutation may have occurred specifically in a subset of subclone 4 cells.

\section{Ploidy of CTCs Gives Insight into Tumor Evolution through Genomic Duplication}

Based on the CNA profiles, we hypothesized that subclone 4 might have been created by duplication of subclone 2. Hence, to test the ploidy of CTCs, we performed fluorescence in situ hybridization with a probe for the centromeric region of Chromosome 6 (Fig. 6A). As this region was affected by a heterozygous loss as found by CNA analysis in subclone 1-3 cells, one focus marks diploid cells, whereas two foci point toward a tetraploid CTC for these subclones. Analysis of CTCs of draw 14, which solely contains cells of clone 1-3, 
A

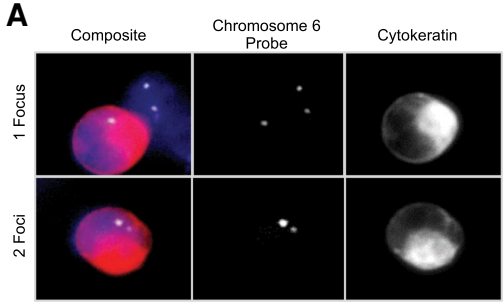

B

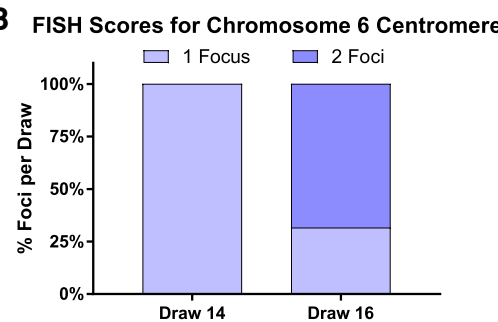

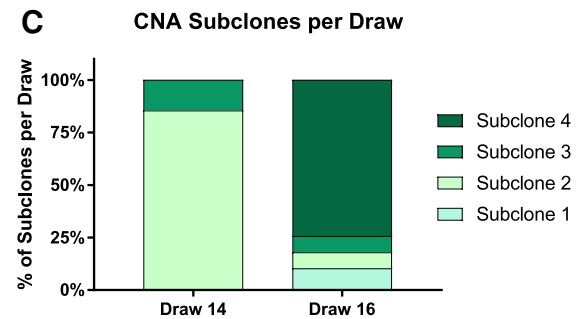

Figure 6. Assessment of ploidy of CTCs by fluorescence in situ hybridization (FISH). (A) Representative images of CTCs stained with DAPI (blue), CK--Alexa-555 (red), Chromosome 6 probe (white), and CD45-Cy5 (green, not shown). Composite includes DNA staining, $\mathrm{CK}^{-}$expression, and Chromosome 6 probe. CTCs and surrounding WBCs were scored for number of Chromosome 6 foci. (B) Percentage of cells with one or two foci were calculated for each draw. (C) Percentage of CNA subclones are shown for each draw. We find approximately the same number of clone 4 cells as CTCs with two foci.

finds only diploid cells (Fig. 6B). The first time cells with two foci were detected was with the appearance of subclone 4 at draw 16 (Fig. 6B). Subclone 4 is copy number normal for Chromosome 6, meaning two foci mark a diploid cell. The percentage of cells with two foci in draw 16 is comparable to the percentage of CTCs of subclone 4 (Fig. 6B,C), indicating that subclone 4 might have been created by duplication of multiple chromosomes of clone 2 as described by Navin et al. followed by additional misassortment of arms (Navin et al. 2011).

\section{DISCUSSION}

Our goal in this study was to shed light on the biology of treatment responses through characterization of CTCs and cfDNA in an individual patient throughout the course of treatment and to demonstrate the feasibility and utility of multianalyte liquid biopsies in larger, multipatient studies. In this context, we highlighted how protein and genomic changes in liquid biopsy analytes can provide valuable information about tumor evolution, treatment response, and resistance mechanisms. In short, longitudinal blood sampling of a metastatic breast cancer patient enabled tracing of disease evolution robustly and less invasively than solid tumor biopsies.

First, we demonstrated that CTC enumeration and ctDNA abundance was associated with treatment response and showed similar trends as CA 27.29 levels. Assessment of ER provided insight into drug-induced alterations of ER protein expression. In particular, $\mathrm{ER}^{+}$ CTCs decreased dramatically in the first round of ER-targeted treatment with fulvestrant (draws 1-3), a selective estrogen receptor degrader (SERD), indicating that fulvestrant, but no other drug specifically reduced $\mathrm{ER}^{+} \mathrm{CTCs}$. In contrast, the second round of fulvestrant treatment (draws 13-15) was less effective in eliminating $\mathrm{ER}^{+}$cells, possibly because of acquired mutations in the ESR1 gene, which have been linked to reduced efficacy of fulvestrant binding (Weis et al. 1996; Jeselsohn et al. 2014; Toy et al. 2017).

Single-cell CNA analysis revealed the presence of three genomically related subclones, with a fourth subclone appearing 3.5 years after trial initiation. It is striking that these three subclones persisted throughout various treatments, varying only in relative fraction, indicating high genomic stability. Comparative analysis of CNA profiles of tissue biopsies and CTCs found only subclone 1 in the tissue taken at diagnosis, whereas subclone 2 cells dominated the liver metastasis detected 2.5 years later. Because of the time gap between the breast/ bone biopsy and the first liquid biopsy, it is unclear whether subclones 2 and 3 developed in the breast/bone in that interval or were present at diagnosis, but below the detection limit. Although the clonal origin is not clear, we can conclude that matching CNA profiles of CTCs to 
COLD SPRING HARBOR Molecular Case Studies
Monitoring genomic evolution at single-cell level

those from the cancerous tissue proves their direct relationship, as all CTC subclones detected by HDSCA are either present in the biopsied tissue or evolutionary related to them.

Plasma DNA analysis revealed not only a positive correlation between the abundance of ctDNA and CTCs but also the genomic relationship between the two. Specifically, we found that CNA profiles of ctDNA mimic the most abundant CTC subclone in each draw. Although plasma-based assays detected the presence and genomic makeup of tumor-derived DNA, single-cell high-content resolution was required to deconvolute the subclones and their relationship with ER protein expression at the cellular level.

In addition to tracing disease burden, therapy response, and gross chromosomal alterations, we monitored the emergence of potential resistance mutations in CTCs and cfDNA using PCR-based sequencing of ESR1 and the targeted Oncomine Breast Hotspot panel, respectively. Given the strong ER staining and high positivity of ER in the breast biopsy and cells of the first blood draw, it is not surprising that various ESR1 mutations (Y537N, Y537S, D538G) (Cancer Genome Atlas Network 2012; Schiavon et al. 2015; Chandarlapaty et al. 2016; Fribbens et al. 2016) were detected in the cfDNA, single CTCs, and tissue from the liver biopsy after treatment with a SERD. These mutations have been associated by other groups with reduced fulvestrant efficiency and hormone therapy resistance by promoting ligand-independent activation (Weis et al. 1996; Yu et al. 2014; Chandarlapaty et al. 2016; Chu et al. 2016; Toy et al. 2017). Single-cell SNV analysis found mutations in amino acid 537 to be mutually exclusive from those in amino acid 538 , indicating the coevolution of multiple resistance pathways. Interestingly, all ESR1-mutated cells expressed nuclear ER, signifying ER pathway activation. This is an important observation, because it cautions that nuclear ER expression does not necessarily translate to clinically targetable ER. In addition to ESR1 mutations, a TP53 mutation was detected after chemotherapy treatment and a PIK3CA mutation was first found together with the appearance of subclone 4. Although the one detected PIK3CA mutant cell exhibited chromosomal rearrangements characteristic of subclone 4, more data is needed to establish a direct relationship. Co-occurrence of TP53 and PIK3CA mutations has been reported as worse clinical outcome when compared to TP53 or PIK3CA mutations alone (Croessmann et al. 2017). Aside from the likely treatment-induced ESR1 mutations, and the late appearing TP53 and PIK3CA lesions, we did not detect additional point mutations, indicating that the cancer, particularly in its early development, may have been largely driven by CNAs.

Pathway analysis of 42 commonly altered genes in breast cancer revealed that CNAs of the evolutionary first subclone affect a variety of genes associated with hallmarks of cancer as described by Weinberg et al. (Hanahan and Weinberg 2000). Through the altered dosage of affected genes and their products these cells gained the ability (1) to evade apoptosis (ARID1A) (Shen et al. 2015), (2) accumulate mitotic errors (CDH1) (Lecuit and Yap 2015; Bajrami et al. 2018), (3) diminish their DNA repair (BRCA2) (Venkitaraman 2009), and (4) sustain proliferative signaling (RB1) (Giacinti and Giordano 2006). In contrast, genes altered in subclone 4 such as MYC and APC (Alevizopoulos et al. 1997; Eytan et al. 2006) primarily impact checkpoints in the cell cycle. Together with the TP53, ESR1, and newly acquired PIK3CA point mutations, these alterations are consistent with increased cyclin $D$ abundance, and eventually enhanced proliferation (Rocha et al. 2003; Presti and Quaquarini 2019). In short, CNAs of subclone 1 impact a variety of mechanisms required for tumor development, whereas later CNAs of subclone 4 specifically promote cell cycle transition. This could explain why chemotherapy has resulted in both biochemical response and clinical improvement from draws 6 and 11 in the absence of subclone 4 . In contrast, in the presence of subclone 4, chemotherapy agents as well as the CDK4/6 inhibitor might not have been sufficient to overcome the additional proliferative stimuli. Although ESR1 mutations could have resulted in decreased response to endocrine therapy, we propose that the combination of new CNAs and SNVs at draw 16 possibly resulted in multitreatment failure with the patient passing away shortly after. Yet, the detection of the 
PIK3CA SNV could have indicated alternative treatment options with targeted inhibitors such as alpelisib (which was not available at the time).

In summary, these results demonstrate that a combined solid and liquid biopsy analysis across multiple time points and integrated analysis of bulk and single-cell analytes can provide a high-resolution view of tumor evolution under treatment pressure. Although formalin-fixed paraffin-embedded (FFPE) tissue and cfDNA can provide insight into protein expression and genomic aberrations respectively, neither can compete with the ready access nor the single-cell resolution required for tracing tumor evolution enabled by characterization of CTCs. cfDNA, however, can be leveraged for multigene SNV analysis, which is currently too labor-intensive on a single-cell level, whereas tissue biopsies inform about the tumor's histopathology. We believe that liquid biopsy analysis of both CTCs and cfDNA should become a complementary tool to current standard-of-care solid biopsies. This would allow for minimally invasive follow-up of patients throughout their treatments with the added advantage of detecting acquired therapy resistance mechanisms and guiding treatment selection.

In the future, integrating additional assays such as the assessment of ESR1 methylation status, single-cell RNA sequencing (scRNA-seq), and multiplex proteomics as well as characterizing the circulating tumor microenvironment could all provide an even deeper characterization of a patient's tumor, its evolution, and response to therapy (Goon et al. 2009; Chung et al. 2017; Mastoraki et al. 2018; Jackson et al. 2020; Rao et al. 2020). In addition, recent studies have investigated the biological features of cfDNA, such as nucleosome positioning, fragment size analysis, and copy-number alteration analysis as a measure for disease outcome (Snyder et al. 2016; Mouliere et al. 2018; Paymaneh et al. 2018). Each of these assays has been proven or shown great potential to be clinically relevant for either diagnosis, prognosis, or assessing response to therapy (Radovich et al. 2020). Hence, it is essential to expand on and replicate our findings in a larger cohort of patients to substantiate the utility of longitudinal multianalyte liquid biopsy in metastatic breast cancer and to incorporate additional analytes for a comprehensive liquid biopsy.

\section{MATERIALS AND METHODS}

\section{Collection and Processing of Blood Samples}

Patient peripheral blood samples were collected in Streck DNA tubes according to the approved protocol established by the Institutional Review Board of Billings Clinic. We note that this was a retrospective study and results were not used to influence treatment decisions. After collection, blood samples were shipped overnight to the Kuhn-Hicks laboratory, initially at The Scripps Research Institute (TSRI) and subsequently University of Southern California, and were processed within $48 \mathrm{~h}$ of the blood draw consistent with previously validated protocols (Rodriguez-Lee et al. 2018). Sample preparation was performed as previously described (Marrinucci et al. 2012; Dago et al. 2014) with an additional plasma collection step. In brief, blood plasma was separated by centrifugation for $10 \mathrm{~min}$ at $2000 \mathrm{~g}$. Collected plasma was centrifuged again for $10 \mathrm{~min}$ at $14000 \mathrm{~g}$ to remove WBCs and platelets and frozen at $-80^{\circ} \mathrm{C}$ for further analysis. The extracted plasma volume was replenished with $1 \times$ PBS. Blood samples underwent erythrocyte lysis in ammonium chloride solution and the nucleated cells were resuspended in PBS to create a monolayer of cells on proprietary celladhesion slides (Marienfeld). Slides were incubated for $40 \mathrm{~min}$ at $37^{\circ} \mathrm{C}$, treated with $2 \% \mathrm{BSA}$, and stored at $-80^{\circ} \mathrm{C}$ for further morphological and genomic analysis.

\section{Immunofluorescence Staining and CTC Enumeration}

For this study, we used a four-color version of the published HDSCA workflow (Marrinucci et al. 2009; Rodriguez-Lee et al. 2018) in which the ER status was assessed in the $\mathrm{CK}^{+}$, 
CD45- CTC population. Briefly, the cells were labeled using mouse monoclonal CK19 (1:100; Dako) and panCK (1:100; Sigma-Aldrich) to identify CK ${ }^{+}$cells. ER ${ }^{+}$CTCs were identified using the SP1 clone (1:250, Thermo Fisher Scientific). Secondary antibodies conjugated with Alexa 555 goat (1:500) and Invitrogen Alexa 488 goat anti-rabbit (1:1000) were used to visualize the CK and ER primary antibodies, respectively. Alexa Fluor 647 conjugated mouse anti-human CD45 (1:125, AbD Serotec) was used to identify the white blood cells. DNA was stained with DAPI. CTC enumeration was initialized using a high-throughput fluorescence microscope at $10 \times$ magnification. Presumptive CTCs were identified as DAPI/CK ${ }^{+}$ and $\mathrm{CD}_{45} 5^{-}$. For draws with $>3000 \mathrm{CTCs} / \mathrm{mL}, \mathrm{CTC}$ abundance was approximated by counting a subset of cells and extrapolating to the full set. The expression and subcellular localization of the estrogen receptor was simultaneously measured, and CTCs were evaluated by identifying the presence $\left(E R^{+}\right)$or absence $\left(E R^{-}\right)$of nuclear ER staining. To determine phenotypic differences of cells within a draw, cells were analyzed for cellular/nuclear shape and size at $10 \times$ and $40 \times$ magnification in $R$ using EBImage and ggfortify. Data was visualized with $R$ and GraphPad Prism.

\section{Isolation of Single Cells}

The identified CTCs were subsequently relocated and imaged at $40 \times$ for detailed morphometric analysis. To retrieve cells for genomic analysis, an Eppendorf TransferMan NK2 micromanipulator was used to capture the cell of interest in a micropipette and transfer it to a PCR tube containing $2 \mu \mathrm{L}$ of lysis buffer ( $200 \mathrm{mM} \mathrm{KOH} ; 50 \mathrm{mM}$ DTT). The lysate was frozen and stored at $-80^{\circ} \mathrm{C}$ for genomic processing. Decontamination of micropipettes and microscope stage was performed 30 min prior to each cell capture procedure.

The lysed cell mixture was thawed and underwent whole-genome amplification (WGA) and sequencing library construction as previously reported (Dago et al. 2014; Thiele et al. 2019). Briefly, WGA was done using the WGA4 Genomeplex Single Cell Whole-Genome Amplification Kit (Sigma-Aldrich) followed by purification with the QIAquick PCR Purification Kit (QIAGEN). DNA concentration was measured using the Qubit Fluorometer system (Thermo Fisher Scientific), and fragment size distribution was measured with the Agilent 2100 Bioanalyzer (High-sensitivity DNA Kit, Agilent Technologies). Single-cell Illumina sequencing libraries were created using the Illumina paired indexing system, and pools of up to 96 cells were sequenced at the USC Dornsife Sequencing Core to generate $\sim 500,000$ mapped reads per sample (minimum 250,000).

\section{cfDNA Isolation and Illumina Whole-Genome Library Construction}

Plasma was thawed and cfDNA was extracted with the QIAamp Circulating Nucleic Acid Kit (QIAGEN) according to the manufacturer's instructions. DNA concentration was measured using Qubit Fluorometric Quantitation (Thermo Scientific). Illumina DNA sequencing libraries were constructed with the NEBNext Ultra II DNA Library Prep Kit (New England Biolabs) according to manufacturer's instructions and barcoded with Multiplex Oligos for Illumina (New England Biolabs). The sample size distribution of both the extracted DNA and the sequencing library was measured with the Agilent 2100 Bioanalyzer (High-sensitivity DNA Assay and Kit, Agilent Technologies). Samples were sequenced at low depth to generate $\sim 500,000$ mapped reads per sample (minimum 250,000).

\section{Histological Evaluation of FFPE Tissue Samples}

As part of the routine clinical workup, the breast needle core biopsy was assessed for the degree of staining as well as percentage of stained nuclei of the ER (monoclonal mouse antihuman ER [alfa], clone 1D5 from Dako) and PR (monoclonal mouse anti-human PR [alfa], clone PgR 636 from Dako). In addition, HER2/neu gene copy was determined by FISH using 
COLD SPRING HARBOR Molecular Case Studies
Monitoring genomic evolution at single-cell level the FDA approved PathVysion Test Kits from Vysis, Inc. Copies of the HER2/neu gene and Chromosome 17 were determined by FISH and probes for HER2/neu gene locus and centromeric position of Chromosome 17.

\section{DNA Extraction of FFPE Tissue and Illumina Library Construction}

FFPE tissue samples of the primary breast as well as bone and liver metastasis were microdissected and DNA was extracted with the AllPrep DNA/RNA FFPE kit according to manufacturer's instructions. Sequencing libraries were constructed with the NEBNext Ultra II DNA Library Prep Kit and barcoded with Multiplex Oligos for Illumina (New England Biolabs) according to manufacturer's instructions. The sample size distribution of the sequencing library was measured with the Agilent 2100 Bioanalyzer (High-sensitivity DNA Assay and Kit, Agilent Technologies) and the concentration was measured with Qubit (Thermo Fisher Scientific). Samples were sequenced at USC Core facilities.

\section{Copy-Number Alteration Analysis}

Bioinformatic analysis for copy-number profiling was performed as previously published (Baslan et al. 2015). Briefly, Illumina sequence reads were deconvoluted based on sample barcodes and PCR duplicates were removed. The binned ratios were normalized according to guanine-cytosine (GC) content of each bin and mapped to 20,000 bins averaging $125 \mathrm{kbp}$ of uniquely mapping sequence across the human genome (hg19, Genome Reference Consortium GRCh37, UCSC Genome Browser database). Read count data was segmented using the CBS segmentation algorithm and copy-number profiles were generated from segmented bin count data and presented as ratios to the genome-wide median (Baslan et al. 2012). The hierarchical clustering was performed in $R$ using the heatmap. 2 function in the ggplots package. Cells were clustered by Ward's method with Manhattan distance by their median centered data. Cutoffs for gains and losses were 1.25 and 0.75 over the median, respectively (Baslan et al. 2015).

\section{Determination of ctDNA Fraction in Plasma}

The ctDNA percent was estimated by diluting the single cell amplitudes until they matched those of the cfDNA. We first determined the dilution factor (dilution factor $=(100-$ percent)/ percent), which in turn was used to determine the percent ctDNA (percent ctDNA = (single cell value + dilution factor)/(dilution factor +1$)$ ). ctDNA fractions calculated with this method were comparable to those derived by ichorCNA (Adalsteinsson et al. 2017).

\section{ESR1 and PIK3CA Single-Cell SNV Analysis}

Amplicons of single cells as well as extracted DNA from plasma and FFPE tissue blocks were tested for point mutations in the ligand-binding domain of ESR1. We used a single primer set (Fwd: TACAGTAACAAAGGCATGGAGCA, Rev: CGATGAAGTAGAGCCCGCAG) to amplify the region of interest and PCR products were sequenced using Sanger sequencing. Additionally, a subset of cells was tested for PIK3CA mutations (Fwd: CCAGAG GGGAAAAATATGACA, Rev: AGCACTTACCTGTGACTCCA). Data was analyzed using QSVanalyzer (University of Leeds) (Carr et al. 2009) and KNIME (Michael et al. 2008). Cells with a raw intensity ratio of $>80$ were called wild-type and those with a raw intensity ratio $<20$ were called mutant. The remaining cells were excluded from the analysis.

\section{SNV Analysis of cfDNA}

cfDNA of 13 blood draws was tested for multiple hotspot mutations using the Oncomine Breast Assay v2 (A35865, Thermo Fisher Scientific) in combination with the lon Torrent S5 (Thermo Fisher Scientific). Where available, 20 ng cfDNA was used as starting material. 
The assay examines 152 hotspots, three copy-number genes, and the full length of the TP53 gene. Data was processed with the Oncomine Breast Liquid Biopsy w1.3 workflow on Ion Reporter. Details on total reads, mapped reads, and coverage are summarized in Supplemental Table S1.

\section{Whole-Exome Sequencing of FFPE Tissue}

Whole-exome sequencing libraries were constructed from the whole-genome libraries of the three tissue biopsies with the Illumina TruSight Exome Library Preparation kit (TG-141-1001, Illumina Inc) and each sample was sequenced on Illumina NextSeq 550 and HiSeq 2500 using paired-end 150- and 100-bp sequencing modes, respectively. Alignment on the reference genome (hg19) was made with BWA MEM (v0.7.17) (Li 2013). Aligned reads from both runs were merged for downstream analysis. PCR duplicates were removed using GATK (v4.1.8.1) (McKenna et al. 2010). Specific variants detected in cfDNA samples by the Oncomine Breast Assay v2 were visualized by Integrative Genomics Viewer (IGV) (Robinson et al. 2011). Variants were called if $\geq 2$ more reads were altered. Details on total reads, mapped reads, and coverage are summarized in Supplemental Table S2.

\section{Fluorescence In Situ Hybridization of CTCs}

Slides were stained with DAPI, CK, and CD45 antibody cocktails, scanned and imaged as described above. Once CTC candidates were identified, slides were washed in $2 \times$ SSC buffer and gradually dehydrated in ethanol. The hybridization solution with a probe against the centromeric region of Chromosome 6 (Biocare Medical) was added onto the slides, and the slides were sealed. Probe and cellular DNA were denatured for $3 \mathrm{~min}$ at $70^{\circ} \mathrm{C}$. Hybridization took place overnight at $37^{\circ} \mathrm{C}$ in a humidity chamber for $16-24 \mathrm{~h}$. Slides were then washed in $0.4 \times$ SSC- $0.1 \%$ Tween for $10 \mathrm{~min}$ at $40^{\circ} \mathrm{C}$ and $2 \times$ SSC for $5 \mathrm{~min}$ at room temperature, covered with antifade mounting medium, and imaged using fluorescence microscopy.

\section{ADDITIONAL INFORMATION}

\section{Data Deposition and Access}

All data discussed in this manuscript are either included in the main manuscript text or in its Supplementary Information Files. Some of the data can be accessed through our website http://pivot.usc.edu/. The sequencing data of the single cells, cfDNA, and FFPE is available through the BloodPAC Data Commons Accession ID "BPDC000117"; URL: https://data .bloodpac.org/dashboard/Public/open-links/BPDC000117/index.html.

\section{Ethics Statement}

This study was approved by the Institutional Review Board of Billings Clinic (BC) and the University of Southern California (USC) and was conducted in accordance with the Declaration of Helsinki and the International Conference on Harmonization (IHC) E6 GCP guidelines. Associated IRBs were 13.10 (BC), Pro0044182 (BC), UP-14-00330 (USC), and UP-14-00523 (USC). The patient provided written consent stating the approval of the use of her blood and tissue specimen as well as her medical history for research use and publication.

\section{Acknowledgments}

First and foremost, we thank the patient, who contributed her blood and tissue specimens to research and without whom this study would not have been possible. We thank her family and caregivers for supporting her on her journey. Appreciations also to nurse Tauna 
Competing Interest Statement

A.K., J.N., and P.K. are shareholders in Epic Sciences, Inc. J.H. is on the Advisory Board of Epic Sciences, Inc.

Received August 14, 2020; accepted in revised form November 15, 2020
Jeffrey and other team members at Billings Clinic for the blood sample collection and Xiomara Villasenor and the rest of our technical team of USC for processing and cryobanking the blood samples. Nickolas Matsumoto, Shoujie Chai, and Varsha Sundaresan provided support in the technical data analysis.

\section{Author Contributions}

L.W., L.X., J.N., A.K., A.E.D., P.K., and J.B.H. provided oversight of the project and conceptualized ideas. M.R.-L. and L.W. enumerated CTCs. L.W. scored cells for ER positivity and performed phenotypic image analysis. L.X., A.E.D., D.M., and L.W. isolated single cells, performed WGA, and prepared NGS libraries. L.W. and D.M. performed single-cell ESR1 analysis. L.W. isolated cfDNA and performed cfDNA CNA analysis. L.X. performed SNV analysis of cfDNA as well as whole-exome sequencing on FFPE samples. S.R.-V. performed copynumber alteration analysis of FFPE tissue. L.W. and K.X. tested cells for ploidy by FISH. R.N. and R.K.P. provided technical support and aided in the data analysis. M.R.-L. coordinated with clinical site, and C.R. supervised sample acquisition. J.N. recruited the patient into the study and provided clinical insights. L.W., L.X., J.N., P.K., and J.B.H. prepared the manuscript with edits from R.K.P., S.R.-V., D.M., C.R., and A.K.

\section{Funding}

P.K. and J.B.H. are supported in part by grant awards ID numbers BCRF-17-087 and BCRF18-089 and awards prior to 2016 from the Breast Cancer Research Foundation. P.K. was supported by the National Cancer Institute, National Institutes of Health, under Contract No. HHSN261200800001E. The content of this publication does not necessarily reflect the views of policies of the Department of Health and Human Services nor does mention of trade names, commercial products, or organizations imply endorsement by the U.S. Government. J.N. was supported in part by award number P30CA014089 from the National Cancer Institute. The content is solely the responsibility of the authors and does not necessarily represent the official views of the National Cancer Institute or the National Institutes of Health. L.W. was supported by the Alan Joseph Endowed Fellowship.

\section{REFERENCES}

Abbosh C, Birkbak NJ, Wilson GA, Jamal-Hanjani M, Constantin T, Salari R, Le Quesne J, Moore DA, Veeriah S, Rosenthal R, et al. 2017. Phylogenetic ctDNA analysis depicts early-stage lung cancer evolution. Nature 545: 446-451. doi:10.1038/nature22364

Aceto N, Bardia A, Miyamoto DT, Donaldson MC, Wittner BS, Spencer JA, Yu M, Pely A, Engstrom A, Zhu H, et al. 2014. Circulating tumor cell clusters are oligoclonal precursors of breast cancer metastasis. Cell 158: 1110-1122. doi:10.1016/j.cell.2014.07.013

Adalsteinsson VA, Ha G, Freeman SS, Choudhury AD, Stover DG, Parsons HA, Gydush G, Reed SC, Rotem D, Rhoades J, et al. 2017. Scalable whole-exome sequencing of cell-free DNA reveals high concordance with metastatic tumors. Nat Commun 8: 1324. doi:10.1038/s41467-017-00965-y

Ahlborn LB, Rohrberg KS, Gabrielaite M, Tuxen IV, Yde CW, Spanggaard I, Santoni-Rugiu E, Nielsen FC, Lassen U, Mau-Sorensen M, et al. 2019. Application of cell-free DNA for genomic tumor profiling: a feasibility study. Oncotarget 10: 1388-1398. doi:10.18632/oncotarget.26642

Alevizopoulos K, Vlach J, Hennecke S, Amati B. 1997. Cyclin E and c-Myc promote cell proliferation in the presence of p16INK4a and of hypophosphorylated retinoblastoma family proteins. EMBO J 16: 5322-5333. doi:10.1093/emboj/16.17.5322

Bajrami I, Marlow R, van de Ven M, Brough R, Pemberton HN, Frankum J, Song F, Rafiq R, Konde A, Krastev DB, et al. 2018. E-cadherin/ROS1 inhibitor synthetic lethality in breast cancer. Cancer Discov 8: 498-515. doi:10.1158/2159-8290.CD-17-0603

Baslan T, Kendall J, Rodgers L, Cox H, Riggs M, Stepansky A, Troge J, Ravi K, Esposito D, Lakshmi B, et al. 2012. Genome-wide copy number analysis of single cells. Nat Protoc 7: 1024-1041. doi:10.1038/nprot .2012 .039 
Baslan T, Kendall J, Ward B, Cox H, Leotta A, Rodgers L, Riggs M, D'Italia S, Sun G, Yong M, et al. 2015. Optimizing sparse sequencing of single cells for highly multiplex copy number profiling. Genome Res 25: 714-724. doi:10.1101/gr.188060.114

Bettegowda C, Sausen M, Leary RJ, Kinde I, Wang Y, Agrawal N, Bartlett BR, Wang H, Luber B, Alani RM, et al. 2014. Detection of circulating tumor DNA in early- and late-stage human malignancies. Sci Transl Med 6: 224ra224. doi:10.1126/scitranslmed.3007094

Cancer Genome Atlas Network. 2012. Comprehensive molecular portraits of human breast tumours. Nature 490: 61-70. doi:10.1038/nature11412

Carlsson A, Nair VS, Luttgen MS, Keu KV, Horng G, Vasanawala M, Kolatkar A, Jamali M, lagaru AH, Kuschner W, et al. 2014. Circulating tumor microemboli diagnostics for patients with non-small-cell lung cancer. $J$ Thorac Oncol 9: 1111-1119. doi:10.1097/JTO.0000000000000235

Carr IM, Robinson JI, Dimitriou R, Markham AF, Morgan AW, Bonthron DT. 2009. Inferring relative proportions of DNA variants from sequencing electropherograms. Bioinformatics 25: 3244-3250. doi:10.1093/bioinfor matics/btp583

Chandarlapaty S, Chen D, He W, Sung P, Samoila A, You D, Bhatt T, Patel P, Voi M, Gnant M, et al. 2016. Prevalence of ESR1 mutations in cell-free DNA and outcomes in metastatic breast cancer: a secondary analysis of the BOLERO-2 clinical trial. JAMA Oncol 2: 1310-1315. doi:10.1001/jamaoncol.2016.1279

Chu D, Paoletti C, Gersch C, VanDenBerg DA, Zabransky DJ, Cochran RL, Wong HY, Toro PV, Cidado J, Croessmann S, et al. 2016. ESR1 mutations in circulating plasma tumor DNA from metastatic breast cancer patients. Clin Cancer Res 22: 993-999. doi:10.1158/1078-0432.CCR-15-0943

Chung W, Eum HH, Lee HO, Lee KM, Lee HB, Kim KT, Ryu HS, Kim S, Lee JE, Park YH, et al. 2017. Single-cell RNA-seq enables comprehensive tumour and immune cell profiling in primary breast cancer. Nat Commun 8: 15081. doi:10.1038/ncomms15081

Cristofanilli M, Budd GT, Ellis MJ, Stopeck A, Matera J, Miller MC, Reuben JM, Doyle GV, Allard WJ, Terstappen LW, et al. 2004. Circulating tumor cells, disease progression, and survival in metastatic breast cancer. N Engl J Med 351: 781-791. doi:10.1056/NEJMoa040766

Croessmann S, Wong HY, Zabransky DJ, Chu D, Rosen DM, Cidado J, Cochran RL, Dalton WB, Erlanger B, Cravero K, et al. 2017. PIK3CA mutations and TP53 alterations cooperate to increase cancerous phenotypes and tumor heterogeneity. Breast Cancer Res Treat 162: 451-464. doi:10.1007/s10549-017-4147-2

Dago AE, Stepansky A, Carlsson A, Luttgen M, Kendall J, Baslan T, Kolatkar A, Wigler M, Bethel K, Gross ME, et al. 2014. Rapid phenotypic and genomic change in response to therapeutic pressure in prostate cancer inferred by high content analysis of single circulating tumor cells. PLoS One 9: e101777. doi:10.1371/jour nal.pone.0101777

Dawson SJ, Tsui DW, Murtaza M, Biggs H, Rueda OM, Chin SF, Dunning MJ, Gale D, Forshew T, Mahler-Araujo B, et al. 2013. Analysis of circulating tumor DNA to monitor metastatic breast cancer. N Engl J Med 368: 1199-1209. doi:10.1056/NEJMoa1213261

Eytan E, Moshe Y, Braunstein I, Hershko A. 2006. Roles of the anaphase-promoting complex/cyclosome and of its activator Cdc20 in functional substrate binding. Proc Natl Acad Sci 103: 2081-2086. doi:10.1073/pnas .0510695103

Fribbens C, O'Leary B, Kilburn L, Hrebien S, Garcia-Murillas I, Beaney M, Cristofanilli M, Andre F, Loi S, Loibl S, et al. 2016. Plasma ESR1 mutations and the treatment of estrogen receptor-positive advanced breast cancer. J Clin Oncol 34: 2961-2968. doi:10.1200/JCO.2016.67.3061

Giacinti C, Giordano A. 2006. RB and cell cycle progression. Oncogene 25: 5220-5227. doi:10.1038/sj.onc .1209615

Goon PK, Lip GY, Stonelake PS, Blann AD. 2009. Circulating endothelial cells and circulating progenitor cells in breast cancer: relationship to endothelial damage/dysfunction/apoptosis, clinicopathologic factors, and the Nottingham Prognostic Index. Neoplasia 11: 771-779. doi:10.1593/neo.09490

Gorges K, Wiltfang L, Gorges TM, Sartori A, Hildebrandt L, Keller L, Volkmer B, Peine S, Babayan A, Moll I, et al. 2019. Intra-patient heterogeneity of circulating tumor cells and circulating tumor DNA in blood of melanoma patients. Cancers (Basel) 11: 1685. doi:10.3390/cancers11111685

Hanahan D, Weinberg RA. 2000. The hallmarks of cancer. Cell 100: 57-70. doi:10.1016/S0092-8674(00) 81683-9

Heitzer E, Haque IS, Roberts CES, Speicher MR. 2019. Current and future perspectives of liquid biopsies in genomics-driven oncology. Nat Rev Genet 20: 71-88. doi:10.1038/s41576-018-0071-5

Jackson HW, Fischer JR, Zanotelli VRT, Ali HR, Mechera R, Soysal SD, Moch H, Muenst S, Varga Z, Weber WP, et al. 2020. The single-cell pathology landscape of breast cancer. Nature 578: 615-620. doi:10.1038/ s41586-019-1876-x

Jeselsohn R, Yelensky R, Buchwalter G, Frampton G, Meric-Bernstam F, Gonzalez-Angulo AM, Ferrer-Lozano J, Perez-Fidalgo JA, Cristofanilli M, Gómez H, et al. 2014. Emergence of constitutively active estrogen receptor-a mutations in pretreated advanced estrogen receptor-positive breast cancer. Clin Cancer Res 20: 1757-1767. doi:10.1158/1078-0432.CCR-13-2332 
Kasimir-Bauer S, Bittner A-K, Hoffmann O, Hauch S, Sprenger-Haussels M, Storbeck M, Benyaa K, Hahn P, Mach P, Tewes M, et al. 2019. Abstract P4-01-10: the analysis of cell-free DNA and circulating tumor cells from one blood tube might empower treatment decisions in metastatic breast cancer patients. Cancer Res 79: P4-01-10-P04-01-10. doi:10.1158/1538-7445.SABCS18-P4-01-10

Lecuit T, Yap AS. 2015. E-cadherin junctions as active mechanical integrators in tissue dynamics. Nat Cell Biol 17: 533-539. doi:10.1038/ncb3136

Li H. 2013. Aligning sequence reads, clone sequences and assembly contigs with BWA-MEM. arXiv 1303.3997.

Marrinucci D BK, Luttgen M, Bruce RH, Nieva J, Kuhn P. 2009. Circulating tumor cells from well-differentiated lung adenocarcinoma retain cytomorphologic features of primary tumor type. Arch Pathol Lab Med 133: 1468-1471.

Marrinucci D, Bethel K, Kolatkar A, Luttgen MS, Malchiodi M, Baehring F, Voigt K, Lazar D, Nieva J, Bazhenova L, et al. 2012. Fluid biopsy in patients with metastatic prostate, pancreatic and breast cancers. Phys Biol 9: 016003. doi:10.1088/1478-3975/9/1/016003

Mastoraki S, Strati A, Tzanikou E, Chimonidou M, Politaki E, Voutsina A, Psyrri A, Georgoulias V, Lianidou E. 2018. ESR1 methylation: a liquid biopsy-based epigenetic assay for the follow-up of patients with metastatic breast cancer receiving endocrine treatment. Clin Cancer Res 24: 1500-1510. doi:10.1158/1078-0432 .CCR-17-1181

McKenna A, Hanna M, Banks E, Sivachenko A, Cibulskis K, Kernytsky A, Garimella K, Altshuler D, Gabriel S, Daly M, et al. 2010. The Genome Analysis Toolkit: a MapReduce framework for analyzing next-generation DNA sequencing data. Genome Res 20: 1297-1303. doi:10.1101/gr.107524.110

Michael R, Berthold NC, Dill F, Gabriel TR, Kötter T, Meinl T, OhI P, Sieb C, Thiel K, Wiswedel B. 2008. KNIME: the Konstanz Information Miner. Data analysis, machine learning and applications studies in classification, data analysis, and knowledge organization. Springer, Berlin.

Morad G, Carman CV, Hagedorn EJ, Perlin JR, Zon LI, Mustafaoglu N, Park TE, Ingber DE, Daisy CC, Moses MA. 2019. Tumor-derived extracellular vesicles breach the intact blood-brain barrier via transcytosis. ACS Nano 13: 13853-13865. doi:10.1021/acsnano.9b04397

Mouliere F, Chandrananda D, Piskorz AM, Moore EK, Morris J, Ahlborn LB, Mair R, Goranova T, Marass F, Heider K, et al. 2018. Enhanced detection of circulating tumor DNA by fragment size analysis. Sci Transl Med 10: eaat4921. doi:10.1126/scitranslmed.aat4921

Murtaza M, Dawson SJ, Tsui DW, Gale D, Forshew T, Piskorz AM, Parkinson C, Chin SF, Kingsbury Z, Wong AS, et al. 2013. Non-invasive analysis of acquired resistance to cancer therapy by sequencing of plasma DNA Nature 497: 108-112. doi:10.1038/nature12065

Murtaza M, Dawson SJ, Pogrebniak K, Rueda OM, Provenzano E, Grant J, Chin SF, Tsui DWY, Marass F, Gale D, et al. 2015. Multifocal clonal evolution characterized using circulating tumour DNA in a case of metastatic breast cancer. Nat Commun 6: 8760. doi:10.1038/ncomms9760

Navin N, Kendall J, Troge J, Andrews P, Rodgers L, Mclndoo J, Cook K, Stepansky A, Levy D, Esposito D, et al. 2011. Tumour evolution inferred by single-cell sequencing. Nature 472: 90-94. doi:10.1038/nature09807

O'Leary B, Hrebien S, Morden JP, Beaney M, Fribbens C, Huang X, Liu Y, Bartlett CH, Koehler M, Cristofanilli $M$, et al. 2018. Early circulating tumor DNA dynamics and clonal selection with palbociclib and fulvestrant for breast cancer. Nat Commun 9: 896. doi:10.1038/s41467-018-03215-x

Palmirotta R, Lovero D, Cafforio P, Felici C, Mannavola F, Pelle E, Quaresmini D, Tucci M, Silvestris F. 2018. Liquid biopsy of cancer: a multimodal diagnostic tool in clinical oncology. Ther Adv Med Oncol 10: 1758835918794630. doi:10.1177/1758835918794630

Parikh AR, Leshchiner I, Elagina L, Goyal L, Levovitz C, Siravegna G, Livitz D, Rhrissorrakrai K, Martin EE, Van Seventer EE, et al. 2019. Liquid versus tissue biopsy for detecting acquired resistance and tumor heterogeneity in gastrointestinal cancers. Nat Med 25: 1415-1421. doi:10.1038/s41591-019-0561-9

Paymaneh D, Malihi MM, Welter L, Liu ST, Miller ET, Cadaneanu RM, Knudsen BS, Lewis MS, Carlsson A, Velasco CR, et al. 2018. Clonal diversity revealed by morphoproteomic and copy number profiles of single prostate cancer cells at diagnosis. Converg Sci Phys Oncol 4: 015003. doi:10.1088/2057-1739/aaa00b

Presti D, Quaquarini E. 2019. The PI3K/AKT/mTOR and CDK4/6 pathways in endocrine resistant HR ${ }^{+} / \mathrm{HER}^{-}$ metastatic breast cancer: biological mechanisms and new treatments. Cancers (Basel) 11: 1242. doi:10 .3390/cancers11091242

Radovich M, Jiang G, Hancock BA, Chitambar C, Nanda R, Falkson C, Lynce FC, Gallagher C, Isaacs C, Blaya $\mathrm{M}$, et al. 2020. Association of circulating tumor DNA and circulating tumor cells after neoadjuvant chemotherapy with disease recurrence in patients with triple-negative breast cancer: preplanned secondary analysis of the BRE12-158 randomized clinical trial. JAMA Oncol 6: 1410-1415. doi:10.1001/jamaoncol.2020 .2295 .

Rao M, Oh K, Moffitt R, Thompson P, Li J, Liu J, Sasson A, Georgakis G, Kim J, Choi M, et al. 2020. Comparative single-cell RNA sequencing (scRNA-seq) reveals liver metastasis-specific targets in a patient with small intestinal neuroendocrine cancer. Cold Spring Harb Mol Case Stud 6: a004978. doi:10.1101/mcs.a004978 
Robinson JT, Thorvaldsdottir H, Winckler W, Guttman M, Lander ES, Getz G, Mesirov JP. 2011. Integrative genomics viewer. Nat Biotechnol 29: 24-26. doi:10.1038/nbt.1754

Rocha S, Martin AM, Meek DW, Perkins ND. 2003. p53 represses cyclin D1 transcription through down regulation of $\mathrm{Bcl}-3$ and inducing increased association of the p52 NF-kB subunit with histone deacetylase 1 . Mol Cell Biol 23: 4713-4727. doi:10.1128/MCB.23.13.4713-4727.2003

Rodriguez-Lee M, Kolatkar A, McCormick M, Dago AD, Kendall J, Carlsson NA, Bethel K, Greenspan EJ, Hwang SE, Waitman KR, et al. 2018. Effect of blood collection tube type and time to processing on the enumeration and high-content characterization of circulating tumor cells using the high-definition single-cell assay. Arch Pathol Lab Med 142: 198-207. doi:10.5858/arpa.2016-0483-OA

Rossi G, Mu Z, Rademaker AW, Austin LK, Strickland KS, Costa RLB, Nagy RJ, Zagonel V, Taxter TJ, Behdad A, et al. 2018. Cell-free DNA and circulating tumor cells: comprehensive liquid biopsy analysis in advanced breast cancer. Clin Cancer Res 24: 560-568. doi:10.1158/1078-0432.CCR-17-2092

Scher HI, Graf RP, Schreiber NA, Jayaram A, Winquist E, McLaughlin B, Lu D, Fleisher M, Orr S, Lowes L, et al. 2018. Assessment of the validity of nuclear-localized androgen receptor splice variant 7 in circulating tumor cells as a predictive biomarker for castration-resistant prostate cancer. JAMA Oncol 4: 1179-1186. doi:10 .1001/jamaoncol.2018.1621

Schiavon G, Hrebien S, Garcia-Murillas I, Cutts RJ, Pearson A, Tarazona N, Fenwick K, Kozarewa I, LopezKnowles E, Ribas R, et al. 2015. Analysis of ESR1 mutation in circulating tumor DNA demonstrates evolution during therapy for metastatic breast cancer. Sci Transl Med 7: 313ra182. doi:10.1126/scitranslmed .aac7551

Shen J, Peng Y, Wei L, Zhang W, Yang L, Lan L, Kapoor P, Ju Z, Mo Q, Shih le M, et al. 2015. ARID1A deficiency impairs the DNA damage checkpoint and sensitizes cells to PARP inhibitors. Cancer Discov 5: 752-767. doi:10.1158/2159-8290.CD-14-0849

Snyder MW, Kircher M, Hill AJ, Daza RM, Shendure J. 2016. Cell-free DNA comprises an in vivo nucleosome footprint that informs its tissues-of-origin. Cell 164: 57-68. doi:10.1016/j.cell.2015.11.050

Thiele JA, Pitule P, Hicks J, Kuhn P. 2019. Single-cell analysis of circulating tumor cells. Methods Mol Biol 1908: 243-264. doi:10.1007/978-1-4939-9004-7_17

Toy W, Weir H, Razavi P, Lawson M, Goeppert AU, Mazzola AM, Smith A, Wilson J, Morrow C, Wong WL, et al. 2017. Activating ESR1 mutations differentially affect the efficacy of ER antagonists. Cancer Discov 7: 277287. doi:10.1158/2159-8290.CD-15-1523

Venkitaraman AR. 2009. Linking the cellular functions of BRCA genes to cancer pathogenesis and treatment. Annu Rev Pathol 4: 461-487. doi:10.1146/annurev.pathol.3.121806.151422

Vignot S, Besse B, Andre F, Spano JP, Soria JC. 2012. Discrepancies between primary tumor and metastasis: a literature review on clinically established biomarkers. Crit Rev Oncol Hematol 84: 301-313. doi:10.1016/j critrevonc.2012.05.002

Wang C, Mu Z, Ye Z, Zhang Z, Abu-Khalaf MM, Silver DP, Palazzo JP, Jagannathan G, Fellin FM, Bhattacharya $S$, et al. 2020. Prognostic value of HER2 status on circulating tumor cells in advanced-stage breast cancer patients with HER2-negative tumors. Breast Cancer Res Treat 181: 679-689. doi:10.1007/s10549-02005662-x

Weis KE, Ekena K, Thomas JA, Lazennec G, Katzenellenbogen BS. 1996. Constitutively active human estrogen receptors containing amino acid substitutions for tyrosine 537 in the receptor protein. Mol Endocrinol 10: 1388-1398. doi:10.1210/mend.10.11.8923465

Wyatt AW, Annala M, Aggarwal R, Beja K, Feng F, Youngren J, Foye A, Lloyd P, Nykter M, Beer TM, et al. 2017. Concordance of circulating tumor DNA and matched metastatic tissue biopsy in prostate cancer. J Natl Cancer Inst 109: djx118. doi:10.1093/jnci/djx118

Yu M, Bardia A, Aceto N, Bersani F, Madden MW, Donaldson MC, Desai R, Zhu H, Comaills V, Zheng Z, et al. 2014. Cancer therapy. Ex vivo culture of circulating breast tumor cells for individualized testing of drug susceptibility. Science 345: 216-220. doi:10.1126/science.1253533 


\section{COLD SPRING HARBOR Molecular Case Studies}

\section{Treatment response and tumor evolution: lessons from an extended series of multianalyte liquid biopsies in a metastatic breast cancer patient}

Lisa Welter, Liya Xu, Dillon McKinley, et al.

Cold Spring Harb Mol Case Stud 2020, 6: a005819 originally published online November 17, 2020

Access the most recent version at doi: $10.1101 / \mathrm{mcs} . a 005819$
Supplementary http://molecularcasestudies.cshlp.org/content/suppl/2020/11/17/mcs.a005819.D Material C1
References This article cites 62 articles, 17 of which can be accessed free at: http://molecularcasestudies.cshlp.org/content/6/6/a005819.full.html\#ref-list-1
License This article is distributed under the terms of the Creative Commons Attribution-NonCommercial License, which permits reuse and redistribution, except for commercial purposes, provided that the original author and source are credited.
Email Alerting Receive free email alerts when new articles cite this article - sign up in the box at the Service top right corner of the article or click here.

